\title{
RELOCATING OR REDEFINED: A NEW PERSPECTIVE ON URBANIZATION IN CHINA
}

\author{
Li Gan \\ Qing He \\ Ruichao Si \\ Daichun Yi \\ Working Paper 26585 \\ http://www.nber.org/papers/w26585
NATIONAL BUREAU OF ECONOMIC RESEARCH
1050 Massachusetts Avenue
Cambridge, MA 02138
December 2019

The views expressed herein are those of the authors and do not necessarily reflect the views of the National Bureau of Economic Research.

NBER working papers are circulated for discussion and comment purposes. They have not been peer-reviewed or been subject to the review by the NBER Board of Directors that accompanies official NBER publications.

(C) 2019 by Li Gan, Qing He, Ruichao Si, and Daichun Yi. All rights reserved. Short sections of text, not to exceed two paragraphs, may be quoted without explicit permission provided that full credit, including $\odot$ notice, is given to the source. 
Relocating or Redefined: A New Perspective on Urbanization in China

Li Gan, Qing He, Ruichao Si, and Daichun Yi

NBER Working Paper No. 26585

December 2019

JEL No. O18,R31,R52

\begin{abstract}
$\underline{\text { ABSTRACT }}$
China's fast economic growth over the past 40 years has been accompanied by an increasingly rapid rate of urbanization, from about $20 \%$ in the early 1980 s to $60 \%$ in 2018 . In addition to natural population growth, rural-urban migration is generally believed to be a dominant driving force. Motivated by a recent finding of a high housing vacancy rate in urban China, however, we find that a large share of urban population growth comes from community reclassification. These redefined migrants (from communities which were reclassified from rural to urban) accounted for $33.4 \%$ of total urban population growth from 2010 to 2015. Households in reclassified communities share similar characteristics with those from rural villages, particularly in their ownership of housing. Furthermore, we provide evidence that at the prefecture level, the size of redefined migrants is significantly related to residential land supply, and to the proportion of households holding vacant housing units, but not to the change of night-time light. These results suggest that an inaccurate account of urbanization is an important factor for the oversupply of residential housing units in China.

Li Gan

Department of Economics

Texas A\&M University

College Station, TX 77843-4228

and NBER

ganli@tamu.edu

Qing He

Guanghuacun Street 55

China Household Finance Survey

Southwestern University of Finance

and Economics

Chengdu 610074

China

heqing@chfs.cn

\author{
Ruichao Si \\ School of Economics \\ Nankai University \\ 94 Weijin Road \\ Tianjin 300071 \\ China \\ siruichao@nankai.edu.cn \\ Daichun Yi \\ Guanghuacun Street 55 \\ China Household Finance Survey \\ Southwestern University of Finance \\ and Economics \\ Chengdu 610074 \\ China \\ daichunyi@chfs.cn
}

An appendix is available at http://www.nber.org/data-appendix/w26585 


\section{Introduction}

Urbanization has played a key role in economic development since most manufacturing and service production is more efficient in urban areas that benefit from agglomeration (Henderson et al. [2009]). According to the World Urbanization Prospects, the world urban population has grown rapidly from 751 million or $29.3 \%$ of the world population to 4.2 billion or 55\% in 2018 (United Nations 2018]). The majority of this increase came from developed countries. However, more recently, developing countries generated the most urban population growth (Glaeser and Henderson [2017]). China, with one-fifth of the world population, contrubited $28 \%$ of the world urban population growth since 2000 . In fact, between 2000 and 2015, China's urban population increased from 459 million to 771 million, and the urbanization rate increased from $36.2 \%$ to $56.1 \%$.

Accompanied by this most rapid and expansive urban growth in history ${ }^{1}$ is the booming in the urban housing market. Before 1990s, households in urban areas who worked for the state-owned enterprises were assigned housing units by their work units with low rents. In 1993, approximately 40 percent of urban households in China were residing in state-owned housing (Wang 2011]). After a housing reform that took place in 1994, state-owned housing units were no longer provided and private housing market quickly developed. For example, in 2005, the quantity of newly completed residential construction reached 28.4 million square meters in Beijing, which accounted for $13.1 \%$ of the city's existing housing stock (Zheng and Kahn [2008]). Nationwide, Figure 1 illustrates a rising trend of completed residential housing units in urban areas. The total number was almost doubled from 549 million square meters in 2000 to one billion square meters in 2012, in which year it accounted for $4.3 \%$ of the existing housing stock in urban areas. In the United States, on the contrary, the housing units built in urbanized area between 2010 and 2013 were 1.64 million, only accounting for $1.8 \%$ of total housing units by 2013 in urbanzied area.

Recently, however, a widely publicized study by China Household Finance Survey (CHFS)

\footnotetext{
${ }^{1}$ Christensen and McCord 2016
} 
in 2014 and then in 2018 estimated approximately 65 million vacant housing units in urban China..$^{2}$ These vacant units consist of houses and apartments which are not occupied by their owners for a variety of reasons, such as temporary migration or that the homeowners own multiple properties that are not occupied by themselves or anyone else. This number is high not only in absolute values but also in percentages; these units account for $21.4 \%$ of all urban housing units in 2017. Table 1 shows the housing vacancy rates in China and in other economies. Urban China's housing vacancy rate ranks one of the highest among all listed countries or regions.

Partly because of the first-ever estimate on vacancy rate based on the large-sampled nationally representative household survey data in China, and partly because the estimate was surprisingly large, a wide-ranged debate among both academic researchers and real estate developers followed the study in 2014. Many researchers and developers believed at the time that the vacancy rate estimate was too big. Their logic is based upon comparing increments with increments. Although no official data ever exist, it is commonly believed that there would hardly be any vacanct housing before 2000 in urban China. Therefore, one may compare the increments in the number of households and in the number of newlybuilt housing units net of demolished ones. Figure 1 graphically illustrates yearly completed residential housing units and yearly increase in urban households. Between 2000 and 2012 ${ }^{3}$ the total estimated number of newly added urban households was around 92.46 million while that of newly added housing units in urban areas was about 80.96 million. If we compare these two groups and assume that each newly added urban household occupies one unit, it is impossible to find such a large number of vacant units in urban China. In this sense, it is

\footnotetext{
${ }^{2}$ See, for example, New York Times https://www.nytimes.com/2018/12/30/business/china-economyproperty.html; Nikkei Asian Review https://asia.nikkei.com/Spotlight/Cover-Story/China-s-housing-glutcasts-pall-over-the-economy; Bloomberg https://www.bloomberg.com/news/articles/2018-11-08/a-fifth-ofchina-s-homes-are-empty-that-s-50-million-apartments; and numerous others in both English and Chinese media.

${ }^{3}$ The numbers on added housing units in urban areas are from the 2014 China Statistical Yearbook. The last year in which this variable is available is 2012. There is only information on the total size of newly built residential houses on a yearly basis from 1985 to 2012 . We assume the average size per housing unit is 90 square meters. The numbers on the annual demolished urban housing units are estimated based on the 2013 wave of China Household Finance Survey.
} 
puzzling to find almost 50 million vacant units in 2014, or 65 million vacant units in 2018 .

Motivated by these two seemingly contradictory studies, this paper provides a new perspective on urbanization in China; that is, we solve this puzzle by decomposing the growth of urban population while providing a new statistical framework for China's urbanization.

Besides natural population growth from birth and death, urban population growth consists of two main sources: migration from rural to urban areas, referred as relocating migrants in this paper, and urbanization by expansion of urban areas (Wang 2004); Chen and Song [2014]). Residents living in these expanded urban areas are reclassified as urban residents, referred as redefined migrants because they in fact do not relocate. In the literature, the relocating migrants have been generally believed to be a dominant driving force of the overall urbanization process. For example, Zhang and Song 2003 compute the amount of annual increase of urban populatoin by the natural growth and relocating migrants. They find that the latter made dominant contributions to urban population growth from 1978 to 1999. However, we find that quite a large share of newly added urban residents in the first half of the 2010s resulted from the National Bureau of Statistics' (NBS) reclassifying communities from rural to urban. By tracking nearly 700,000 communities from 2009 to 2017 and using their respective rural-urban division codes to identify rural communities that were reclassified as urban, we estimate that redefined migrants accounted for nearly $34 \%$ of all urban population growth during this period.

This paper contributes to the large literature on urbanization in China, both spatially and in urban population size. Spatially, Deng et al. 2008 employ a unique three-period panel data set of high-resolution satellite imagery data to study the extent of and the factors driving urban expansion in China from the late 1980s to 2000. They find that the growth of income and population in a city play powerful roles in China's urban exansion. Lichtenberg and Ding 2009 theoretically demonstrate how fiscal and governance reforms may result in land conversion decisions and long run urban spatial sizes. These papers mainly talk about how urban area expands due to economic activities, for example, land converted from 
agricultural use into industrial or residential uses. Our paper documents and measures the spatial expansion of urban areas from a statistical perspective on which urbanization rate is based. In terms of the size of the urban population, we complement the work of Wang [2004 and Chen and Song 2014 by providing the composition estimation in the 2010s. Wang 2004 uses census data from 1990 and 2000 and estimates different sources of urban population growth in 1990s while Chen and Song [2014] use their methods to account for China's urbanization in 2000s 4 However, both of these two papers are only able to measure at the national level. Different from theirs, we could measure different sources at more disaggregated levels on a yearly basis.

Furthermore, employing survey data collected by CHFS at both the household and community levels, we provide evidence that these communities, though statistically reclassified as urban, retain their basic rural characteristics, and residents in these communities continue to share similar living conditions with rural villagers, even after years of reclassification. Moreover they have limited resources to participate in commercial housing markets.

We thus show that urbanized population should not be treated equally since a large share of urban population growth comes from the urban land expansion. As a result, previous studies on determinants or consequences of urbanization in China might be misleading. For example, Li and Huang 2015] study how increase in housing prices in Chinese cities might have impacts on household saving behavior. Given that housing prices could be affected by some macro-level factors, they use the province-level changes of urbanization rate as an excluded instrument, which implies that increases in urban population lead to more demand in the urban housing markets, thus increase the price. However, based on our analysis, this does not hold for urban population from reclassification.

In addition, we apply this new urbanization framework to land and housing markets at the prefecture level. Using prefecture-level data, we show that the size of redefined migrants is significantly related to the local land supply, suggesting that a mismeasurement

\footnotetext{
${ }^{4}$ Their method and results will be discussed in Section 2 .
} 
of urbanization might explain the surplus of urban housing units and result in a high vacancy rate, as reported by CHFS.

Thus, our paper also contributes to the literature on the primary land market in China. For example, Zhang et al. [2017] show that government intervention enlarges the impact of positive productivity shocks on housing price appreciation, through mainly the government control over residential land supply. Li 2018 shows that at the prefecture level, land supply could also be determined by the local leaders' career concern.

The rest of the paper proceeds as follows. Section 2 introduces the current rural-urban division rule and proposes a new approach to measure the size of redefined migrants. Section 3 demonstrates the difference of demographic and housing characteristics of redefined migrants, at both the community and household levels. In Section 4, we show how the size of redefined migrants relates to land supply at the prefecture level. Section 5 concludes.

\section{Decomposing Urban Population Growth}

\subsection{Background}

The urbanization rate is the share of the population that resides in urban areas. However, there are actually no universal standards regarding the rural-urban dichotomy. A country's specific standard may also vary over time. One traditional distinction between urban and rural areas is based on the assumption that urban areas, no matter how they are defined, offer a different way of life and usually provide a higher standard of living than rural areas $5^{5}$ According to UNICEF [2012], the urban-rural dichotomy could be based on one or a combination of factors such as administrative or political boundaries, a threshold on population size ${ }^{6}$ population density, and local economic industries/sectors or the presence of urban characteristics (e.g., paved streets, electronic systems).

\footnotetext{
${ }^{5}$ https://unstats.un.org/unsd/demographic/sconcerns/densurb/densurbmethods.htm

${ }^{6}$ In the United States, for example, the Census Bureau identifies two types of urban areas: Urbanized Areas have 5,000 or more people while Urban Clusters have at least 2,500 and less than 5,000 people.
} 
In China, the official standard of rural-urban dichotomy changes with waves of population censuses. In the 1990 census, the rural-urban definitions were entirely based on administrative boundaries (Wang [2004]).7 Rural-urban areas were defined at the third and fourth levels, i.e., the district/county/county-level city and the street/town/township levels. For example, all "districts" 8 were classified as urban (Chan and $\mathrm{Hu}$ [2003]). The 2000 census modified the previous standard by several criteria that included whether the area has a population density of 1,500 people per squared kilometer; whether the local government is located in the area; and whether the area is contiguous to another area where the local government is located (National Bureau of Statistics [1999]). Compared with the previous standard, districts with less than 1,500 people per square kilometer were no longer all classified as urban areas. Yet, $\mathrm{Yu} 2001$ finds that these two standards yield a very small change, only $0.16 \%$ between 1990 and 2000 population censuses.

The current standard for rural-urban dichotomy was issued in 2008 (National Bureau of Statistics [2008]).9 The new standard defines urban areas at the community level rather than at the county and town levels. Communities are autonomous organizations by their residents. Community leaders are often elected by all residents in the community on a regular basis rather than assigned by higher-level governments. However, communities do receive government funding. In that sense, communities may be considered as the lowest level of administrative unit in China. A community is often referred as "village" in rural areas, and as "community" in urban areas. The total number of communities have been declining since 2009, from 699,089 in 2009 to 673,804 in 2017, at an annual grwoth rate of $-0.5 \%$. Given there are 3,290 county-level administrative units (districts, counties and county-level cities) and 43,805 town-level administrative units (streets, towns and townships) in 2017, each countylevel unit would have 205 communities on average, and each township-level unit would have

\footnotetext{
${ }^{7}$ There are four official administrative levels and one unofficial level. The four official ones are the province/provincial-level city level, the prefecture level, the district/county/county-level city level, and the street/town/township level. The unofficial one is the community level.

${ }^{8}$ Compared with other county-level units, "districts" are usually the core of a prefecture.

${ }^{9}$ The standard (in Chinese) can be found on the official website of the National Bureau of Statistics at http://www.stats.gov.cn/tjsj/tjbz/200610/t20061018_8666.html.
} 
15 communities in 2017. As a result, a community is a much smaller administrative unit than a county or a town. In this sense, this new standard for rural-urban dichotomy would potentially be more accurate than previous ones.

This new standard is solely based on land contiguity by actual construction, which refers to public facilities, residential facilities etc., either completed or under construction. For example, in districts, if a community is contiguous to the district-level government by actual construction, it is classified as urban; otherwise it should be regarded as rural. Industrial parks, economic development zones, colleges or farms that are not contiguous to the area where the local government is located but with population more than 3,000 are also categorized as urban. As a result, this rural and urban division does not directly take population densities, economic activities, or residential infrastructures into major consideration. Hence, there is a possibility that a community is officially reclassified from rural to urban only because its attribute of land contiguity has been changed. It is worth pointing out that the standard does not alter the administrative division, affiliation status or land planning; instead, it is mainly for statistical accounting use.

\subsection{Community ID and Rural-Urban Division Codes}

NBS assigns all communities ID codes and publish them annually since 2009. Figure 2 includes two screenshots from the NBS website: the upper panel shows the links to information for all available years while the lower panel shows the content of each observation unit. Each row represents a community. The first two columns contain community ID and rural-urban division codes respectively while the last column shows the community's name (in Chinese).

The community ID has 12 digits, representing the aforementioned five administrative levels: the first two digits represent province-level administrative units (provinces, autonomous regions and province-level municipalities), the next two digits are for the prefecture and the fifth and sixth digits represent the county (districts, counties and county-level cities). The seventh, eighth and ninth digits represent the town level (streets, towns and townships) while 
the final three digits represent the community 10 They are codified according to the NBS' Coding Rules for Administrative Units at the Town Level and Lower.

The rural-urban division code has five digits. The first two digits represent the village attributes and the last three represent the rural-urban dichotomy. Only the last three digits for each community are available (Note that there are only three digits in the second column of Figure 2]s lower panel.); they are translated from the twelve-digit administrative code and the first two digits of the rural-urban division code. In this three-digit code, the first digit represents the basic rural-urban division: "1" represents urban communities and "2" represents rural villages. The remaining two digits provide a detailed sub-classification.11

Most of the declines of the number of communities come from rural areas. The total number of rural villages has decreased from 519,616 in 2009 to 459,651 in 2017, at an annual grwoth rate of $-1.5 \%$. Among those, villages located in township centers declined most from 23,197 to 16,129 , on average $4.4 \%$ annually, while villages in the suburban areas of townships decreased from 496,419 to 443,522. On the other hand, the total number of urban communities have increased from 179,473 in 2009 to 214,153 in 2017, with an growth rate $2.2 \%$ per year. Specifically, one of the subclassifications that increased most is communities located in the fringe of town and township, from 48,364 in 2009 to 63,991 in 2017, with an annual growth rate of $3.6 \%$. This implies that many of the communities reclassified from rural to urban occured between township centers and town-township fringes, which also serves as evidence that a rural village would be reclassified as an urban community simply due to the change of its attribute of land contiguity by actual construction rather than economic development.

\footnotetext{
${ }^{10}$ Towns and communities that have been confirmed by local governments would be codified from 001 to 399. Those which have not been confirmed would be assigned codes from 400 to 599, indicating that they are virtual administrative units (for example, industrial zones, farms and forestry stations).

${ }^{11}$ For example, 111 reprensents communities in the center of the city while 121 stands for communities in the town centers.
} 


\subsection{Results from Tracking Community ID over Time}

One problem in tracking a community's rural-urban status change is that the community ID might vary across years. According to the coding rule, any change to the type of upper-level administrative unit: ${ }^{12}$ could result in changes to the community ID. Moreover, it can also change when its (upper-level) administrative unit is reorganized ${ }^{13}$

We track community ID codes for all nearly 700,000 communities from 2009 to 2017. Each year, between $2.81 \%$ and $9.43 \%$ of communities have changed codes from the previous year. For these communities, we first look up all available official documentations for adjusted administrative units at the county level and above and manually track those communities whose prefecture- or county-level administrative units have been adjusted. On average $1.1 \%$ communities can be tracked. For administrative adjustments at the town level and community level, we allow town-level administrative units to be readjusted both within the county and across counties. Another $1.1 \%$ on average can be tracked. The rest steps use different combinations of key words to deal with community-level renames or administrative unit readjustments. However, due to lack of geographic data and public information at the community level, we fail to track communities with merges and splits.

The results from tracking communities from 2009 to 2017 are summarized in Tale 2. Three facts are worth discussing. First, our tracking algorithm allows us to track more than $99 \%$ of communities for most two consecutive years. One exception is 2015-2016. In those two years, there was a massive increase in the number of communities in several provinces ${ }^{14}$ Second, combined all years, around 90\% of communities could be tracked. A large proportion

\footnotetext{
${ }^{12}$ For example, a county can be changed into a county-level city or district; a township can be changed into a town.

${ }^{13}$ For example, a county in one prefecture can be assigned to another prefecture. In 2011, Chaohu prefecture in Anhui province had all its districts and counties reassigned. All of Chaohu's districts and counties were assigned to three other prefectures within the province.

${ }^{14}$ For example, the untracked communities in Heilongjiang province in 2015 is only 66. However, it amounted to 2,153 in 2016. In Xinjiang Uygur Autonomous Region, these numbers were 17 and 3,314 respectively. On the other hand, Hunan province experienced a tremendous drop in the number of communities, the untracked of which were 20,866 in 2015 and 4,862 in 2016, possibly due to a large wave of community merge.
} 
of the untracked communities are from a sudden decrease of total number of communities from 2013 to 2014 5 Third, for all 617,770 communities that can be tracked all across years, there are a considerable number of communities with rural-urban status change every year, though this trend has been declining in recent years. In total, from 2009 to 2017, almost 40,000 communities were reclassified from rural villages to urban communities, accounting for $8.5 \%$ of all rural communities in the year 2009 .

\subsection{Measuring the Size of Redefined Migrants}

Table 3 summarizes the tracking results for our study period of 2010-2015. We tracked around 650,000 communities between 2010 and 2015. By analyzing each year's rural-urban division code for those tracked communities, we are able to obtain detailed information on whether each community has had a rural-urban dichotomy change and, if so, the year it was reclassified. Of the 649,182 communities that were tracked during this period, 27,795 were reclassified from rural to urban while 9,983 were reclassified from urban to rural. The percentage of reclassified communities from rural to urban net of those reclassified from urban to rural account for more than $3.7 \%$ of total rural communities in 201016

\subsubsection{Data on Urban Population at the Prefecture Level}

In order to measure the size of redefined migrants between 2011 and 2015, it is necessary to have information on the urban and rural population during this period. The lower the level of administrative units from which we have population data, the more accurate our measurements would be. The urban and rural population at the prefecture level is available at the 2010 census. For the rest years (2011-2015), populatoin information for each prefecture

\footnotetext{
${ }^{15}$ Note that there were 694,664 communities in 2013 and only 671,348 communities in 2014 , almost a $5 \%$ drop in total numbers.

${ }^{16}$ Here we assume that there are no systematic differences between communities reclassified from rural to urban and those from urban to rural as the rural-urban dichotomy mainly relies on land contiguity, which can also be supported by descriptive evidence later shown in Section 3. In fact, many of communities reclassified from urban to rural were either original rural villages that had been reclassified to urban before another reclassification or urban communities that subsequently reclassified to urban again.
} 
is either from its provincial-level statistical yearbooks or from the prefecture's statistical yearbooks or bulletins 17

\subsubsection{Data on Average Population at the Community Level}

In order to measure the number of redefined migrants from the number of reclassified communities, we need to obtain average population for those reclassified communities. The community survey in the China Household Finance Survey at Southwestern University of Finance and Economics provides such information.

So far, there have been four CHFS waves: 2011, 2013, 2015 and 2017. The first wave, from summer 2011, covered 80 counties in 25 provinces and collected data from 8,438 households across 320 community-level administrative units. The second wave in 2013 increased the sample size to 28,143 households distributed in 1,021 communities across 29 provincial-level regions 18 The 2015 and 2017 waves consisted of 37,341 households from 1,362 communities and 40,011 households from 1,417 communities, respectively.

In the CHFS data, communities are sampled using a stratified method with probability proportionate to size sampling. All counties are divided into groups based on their respective GDP per capita rankings; sampled counties are drawn from these groups. Sampled communities are then randomly drawn from those counties. The CHFS dataset is nationally representative. It contains rich micro-level information on household demographics, balance sheets, income and expenditures. Starting from the second wave in 2013, CHFS added a community-level survey to include the community total population and other demographic and geographic information, public infrastructures and local governance. The community survey questions are answered by community officials. Table 4 summarizes all three waves of community survey. On average, the number of residents is 7,308 for an urban community, 1,956 for a rural village, 2,130 for the rural-to-urban reclassified community, and 2,020 for

\footnotetext{
${ }^{17}$ We fail to find this information in most prefectures in provinces like Jilin, Heilongjiang, Tibet, Qinghai and Xinjiang.

${ }^{18}$ There are 31 provincial-level regions in mainland China. Tibet and Xinjiang are the only two that are not included in this survey. Both of them are Minority Autonomous Regions in Western China.
} 
an urban-to-rural reclassified community.

To show the representativeness of the CHFS community survey, we pool all three waves, aggregate at both prefecture and province levels, and compare those with the census data. Figure 3 shows that average community population from the CHFS community survey is quite comparable with that from the 2010 census data. The left panel shows this comparison at the province level. The horizontal axis shows the average population of a rural community within a province calculated as the ratio between the total rural population from 2010 census and the total number of rural communities in 2010. The vertical axis illustrates the average population from the pooled community survey aggregated at each province. The correlation coefficient between these two variables is 0.84 while the estimated coefficient from a regression framework is 1.14, insignificantly different from the 45-degree line. The right panel show this relationship at the prefecture level. We calculate the average population for all 339 prefectures from 2010 census and 155 prefectures from pooled CHFS community survey. The coefficient of correlation is 0.62 . In addition, the estimated coefficient is 1.04 , which is significantly different from 0 but insignificantly different from 1 . As a result, we are confident that the survey data is representative, at least for the rural population information at the prefecture level.

\subsubsection{Measuring the Average Population at the Community Level}

We measure the average population for communities reclassified from rural to urban for each prefecture between 2010 and 2015. For the 36 prefectures of which CHFS has reclassified communities, we use average population from reclassified communities in the pooled CHFS community survey data. For the additional 121 perfectures in the CHFS sample, we use the average population in the rural areas in the CHFS at prefecture level. ${ }^{19}$. For the rest,

\footnotetext{
${ }^{19}$ We have provided some descriptive evidence from Table 4 that the average number of population from reclassified communities (both from rural to urban and from urban to rural) would be higher than the average population in a rural community by around $10 \%$. Therefore, we are likely to underestimate the average population from these communities which leads to a lower bound of the measurement of the overall redefined migrants at the national level.
} 
we set the average population for reclassified communities equal to the province average. ${ }^{20}$ Finally, for the two province-level autonomous regions (Tibet and Xinjiang) from which we have no observations, the average population for reclassified communities in a prefecture is assumed to be the average number of rural population in 2010 census in that prefecture also considering the natural growth from 2010 throughout 2015. ${ }^{21}$

\subsubsection{Measuring the Overall Size of Redefined Migrants}

The size of redefined migrants for each prefecture during 2010-2015 is just the number of communities reclassified from rural to urban net of those reclassified from urban to rural multiplied by the corresponding average population for these reclassified prefectures. Because a small portion of the communities cannot be tracked, the calculated size needs to be scaled up by the ratio of total number of communities to the number of tracked communities during the period. Overall, approximately 33.83 million people were redefined as urban residents. Table 5 shows the size of redefined migrants by provinces across years. It shows that there are large variations in the number of reclassified migrants both between provinces and within provinces across years. In some province-year cells, the number of redefined migrants even exceeds the total number of urban population growth, resulting a negative urban population growth net of redefined migrants. Figure 4 illustrates the distributions of prefectures for both total urban population growth and this net urban population growth between 2010 and 2015. Every prefecture experienced positive total urban population growth. However, the number of net urban population growth is negative for many prefectures, due to a large wave of urban population outflow from these prefectures.

\footnotetext{
${ }^{20}$ We use similar step-wise assumptions as we did at the prefecture level. For those unmatched prefectures, we first assume the average population for reclassified communities is equal to the province average for reclassified communities (We match 124 prefectures.) or rural communities (We match 36 prefectures.).

${ }^{21}$ Data about the natural growth rate are from the National Bureau of Statistics. We are not able to find such information of rural population at the prefecture level. As a result, we need to make assumptions that the variations of natural growth rate during 2010-2015 are not significantly different between rural and urban areas within prefecture.
} 


\subsubsection{Decomposing Urban Population Growth by Year}

Next, we estimate the prefecture-level urban population growth resulting from natural birth and death. For each prefecture, this number is equal to the size of urban population as of 2010 multiplied by its overall rate of natural growth between 2010 and 2015. We conclude that the natural growth of the urban population was approximately 16.62 million.

Finally, the urban population increased by 101.38 million between 2010 and 2015. This total growth consists of natural growth, relocating migrants and the redefined migrants. By subtracting the amount of natural growth and redefined migrants from the total, we estimate that relocating migrants accounted for approximately 50.93 million, around $50.2 \%$ of total urban population growth. Table 6 shows this decomposition across years. Although the size of redefined migrants has been declining, it still accounts for $33.4 \%$ of the overall urban population growth during this period.

\subsection{Comparing Results with Previous Studies}

The current literature offers a couple of papers that focus on how each source contributes to China's urban population growth. Wang [2004], using 1990 and 2000 census, estimates that natural growth accounted for $17 \%$ of the total urban population increase and relocating migrants accounted for $31 \%$. The remaining $52 \%$ came from the establishment of new cities or towns or the expansion of current city or town boundaries; this is contextually similar to the "redefined migrants".

Another related paper is Chen and Song [2014], who employ census data and find that between 2000 and 2010, 20\% of new urban residents are from natural grouwth, 40\% are relocating migrants, and another $40 \%$ are redefined migrants. Their estimates are based on the census tables published by the NBS. Since the census tables only provide the number of residents along both rural/urban residency and agricultural/non-agricultural Hukou dimensions, one can construct a $2 \times 2$ table for each census year after netting out the estimated 
population growth due to birth or death. $2^{22}$ These $2 \times 2$ tables for years 2000 and 2010 imply potentially twelve different population flows from 2000 to 2010. For example, people with agricultural Hukou living in rural areas in 2000 could find themselves in urban areas by 2010 while keeping their agricultural Hukou, or changing to non-agricultural Hukou; or they stay in rural areas while changing their Hukou to be non-agricultural.

In order to back out these population flows, Chen and Song [2014 make following assumptions on the inflows into and outflows from each block between the two waves of census. First, they assume no one who live in rural areas would have non-agricultural Hukou, reducing the number of blocks from four to three in both 2000 and 2010. This assumption reduces the possible population flows from twelve to six. Second, they argue that people who had non-agricultural Hukou in 2000 are generally not allowed to be converted to agricultural Hukou in 2010, eliminating two more population flows. Third, they assume that those who live in urban areas and have agricultural Hukou in 2000 continue to live in urban areas in 2010. As a result of the three assumptions, only three possible population flows remain, i.e., those with agricultural Hukou in rural areas in 2000 move to urban areas in 2010, either keeping their agricultural Hukou, or switching to non-agricultural Hukou, and those with agricultural Hukou in 2000 in urban areas continue to live in urban areas but change to non-agricultural Hukou. The first two movements add up to the total urbanized population. Relying on the relationship between population flows and stocks, the authors managed to back out the total urbanized population during the period.

In the next step, they further break down the urban population with local Hukou and those with non-local Hukou. They assume those with local agricultural Hukou in rural areas in 2000 and non-local agricultural Hukou in urban areas in 2010 are exactly those who migrate from rural to urban areas. Moreover, for simplicity, they assume that the size of population who live in urban areas with agricultural Hukou and move out of their Hukou

\footnotetext{
${ }^{22}$ For example, Table 7-1 from the Long Table of 2010 census reports the size of population with different Hukou registration places (Township, Residents' Committee of Town, Villagers' Committee of Town and Street) and different current places of residence (City, Town and Township).
} 
registration place is roughly equal to the size of population who move back to their Hukou registration place. By doing this, they are able to decompose the rural-urban migrations into two components: (1) change of urban residents with non-local agricultural Hukou net of natural growth and (2) those converting agricultural to non-agricultural Hukou in a place other than where her Hukou was registered. The first component is measured similarly with the first step, using the stock value in census data to back out the flow value. They rely on the China General Social Survey as a supplement to estimate the second component. After estimating the number of relocating migrants, they back out the size of urbanized population due to land reclassification by subtracting relocating migrants from the overall urbanized population.

These papers shed light on the sources of urban population growth. However, they received relatively few attentions, perhaps for the following reasons. First, they treat "redefined migrants" as a residual term, not a direct measure. Put differently, they calculate the size of redefined migrants after measuring the size of relocating migrants and natural growth population; as a result, measurement errors may arise if one wants to study the size of redefined migrants. Second, their methods can only be performed using two consecutive census waves to measure the number for a nationwide 10-year period. In addition, their approach often relies on strong assumptions. For example, in Chen and Song [2014], they assume those who live in urban areas and have agricultural Hukou in 2000 continue to live in urban areas in 2010, which fails to consider the relatively large size of return migrants.

Comparing our result with the two papers, it follows quite a similar trend since 1990.23 Though declining, this relatively large share indicates that urban area expansions are still one of the main factors driving China's increasing urbanization rate.

Unlike Wang 2004 and Chen and Song 2014] who back out the size of rural-urban migration first and then take the residual as urbanization by urban land expansion or reclassification, our approach of decomposing urban population growth takes the opposite

\footnotetext{
${ }^{23}$ Recall that the share of reclassified migrants to the overall urban population growth is $52 \%$ in $1990 \mathrm{~s}$ Wang 2004) and 40\% in 2000s (Chen and Song 2014.
} 
direction. We first measure the size of redefined migrants and then back out the relocating migrants as the residual term. In order to compare our approach with theirs, especially Chen and Song 2014 that employ the most recent census waves, we adopt their method to back out the size of rural-urban relocating migrants as a robustness check using 2010 population census and $20151 \%$ population mini-census.

Employing their methodology, the measured size of redefined migrants was around 47.69 million, 41\% larger than our result. As has been mentioned, our approach tends to be conservative and is likely to underestimate the size of reclassified migrants. Also, in this alternative method, since some information from the $20151 \%$ population mini-census is not available, we have to rely on some linear estimation from its own trend, which is also likely to cause inaccurate measurements. Nevertheless, since both approaches show that there are a large share of urban population growth from urban area expansion (from 33\% to 45\%), we believe that exploring the characteristics of redefined migrants living on those expanded urban areas are of importance to understand the overall urbanization process for the recent decades in China.

\section{Characteristics of Reclassified Communities and Re- defined Migrants}

In Section 2, we measure that redefined migrants accounted for more than $30 \%$ of total urban population growth from 2010 to 2015 . In this section, we use community- and householdlevel survey data from CHFS to explore some characteristics of reclassified communities and redefined migrants, especially their housing behaviors.

\subsection{Characteristics of Reclassified Communities}

We first show descriptive evidence that those reclassified communitites, both from rural to urban and from urban to rural, are more in line with rural villages both demographically 
and in the level of economic development.

Communities from three waves of survey are categroized into four groups: rural, urban, reclassified from rural to urban from 2010 to the survey year ${ }^{24}$ reclassified from urban to rural ${ }^{25}$ For all 3,800 communities pooled in three waves, we are able to track the rural-urban status change for 3,479 communitites and categorize them into the four groups, accounting for more than $91 \%$ of all surveyed communities, in line with the overall tracking rate (Table 2). Table 7 compare the characteristics from these four categories of communities. Variables related to values are measured in $2015 R M B$.

In the community questionnaire, community leaders were asked what type of community they consider their community to be. Results show that $75 \%$ of leaders from reclassified communities regarded themselves as rural, indicating that they were unaware of their own community's rural-urban dichotomy change. What's more, in most of the variables listed in the table, reclassified communities have more characteristics in common with rural villages than their urban counterparts. For example, reclassified communities have an average of 2,130 residents; this is close to the rural population average, and far below the urban community average. Similarly, the average number of registered households in reclassified communities is close to that of rural villages. The questionnaire also asked about basic local facilities, such as number of banks. Data shows that both reclassified and rural communities have less than one bank in their neighborhoods. Conversely, urban communities have nearly two banks on average; this reflects that, in terms of the economic development and infrastructure, these reclassified communities are far less developed than urban communities. Interestingly, all the characteristics for communities reclassified from urban to rural are also very close to traditionally rural villages and reclassified communities. This is straightforward in the sense that the current rural-urban dichotomy adopted by the National Bureau of Statistics is simply based on land contiguity, making both directions of switches

\footnotetext{
${ }^{24}$ For example, if a community was reclassified from rural to urban in 2014 , it was categorized as rural in the 2013 wave but as reclassified in the 2015 wave.

${ }^{25}$ Very few communities experienced the rural-urban dichotomy switch more than once during the study period. We do not include these observations in the comparison as well as later in the empirical analysis.
} 
less dependent on social and economic development of the community.

Beginning in 2015, more questions were added to the survey questionnaire regarding infrastructures and economic activities in a community. These new questions help us make comparisons in more aspects. Demographically, these reclassified communities still share similar characteristics with rural villages, such as the number of registered residents and households. Furthermore, $94 \%$ of the population in reclassified communities has agricultural Hukou. The ratio of communities that keep agricultural land is approximately $17 \%$ in urban communities but over $87 \%$ in reclassified communities; this indicates that the majority of households in these reclassified communities still rely on agricultural activities. Additionally, these reclassified villages have significantly sparser financial services, job trainings, and childcare and eldercare options than urban areas. Moreover, the disposable per capital income for reclassified communities was around 8,000 $R M B$, less than half of that of urban communities.

Columns 5 and 6 in Table 7 compare the difference between reclassified communities from both their rural and urban counterparts. In Column 5 we show the difference between urban and reclassified communities. In all characteristics, the differences are not only large in magnitude but also highly significantly different from zero, almost all at $1 \%$ level. In contrast, Column 6 shows that between rural villages and reclassified communities. While the differences are smaller, most of them are indistinguishable from zero. From such simple comparison, it is clear to see that although reclassified as urban, those commmunities are more aligned with their rural counterparts in terms of demographic and economic development.

\subsection{Characteristics of Redefined Migrant Households}

In addition to community-level comparisons, we also use household survey data to explore whether significant demographic differences exist at the household level. Table 8 shows the demographic and economic information of households in different categories of communities from pooling samples of all four waves $(2011,2013,2015,2017)$. Similar to what we find in 
the community-level data, households living in reclassified communities share more common characteristics with rural households. For example, compared with urban households, they have larger household sizes, more children, and less years of schooling. They are also more likely to hold agricultural Hukou while working in the agricultural sector. With respect to economic activity, their income and consumption levels are much lower.

Moreover, the last two columns of Table 8 also compare the difference for household characteristics. Similar to what we find from the community-level observations, in the household data, we still find asignificant difference between urban households and those from reclassified communities while this difference is much larger than that between rural and reclassified communities.

Using descriptive evidence from both community and household-level comparisons, we conclude that though statistically treated as urban, reclassified communities and redefined migrant households are much more similar to rural villages and rural households than to their urban counterparts.

\subsection{Community Reclassification and Housing Behaviors}

Aimed to solve the urban high-vacancy-rate puzzle, we empirically test whether reclassification from rural to urban had an effect on households' housing behaviors. In order to do this, we pool all four waves of household-level survey data and adopt a fixed-effects model, with the following regression equation:

$$
y_{i j t}=\alpha_{j}+\rho_{t}+\beta \text { Reclassification }{ }_{j t}+X_{i j t}^{\prime} \gamma+\epsilon_{i j t}
$$

where $i$ denotes household, $j$ denotes community and $t$ denotes the survey year. The outcome variable is a dummy variable indicating whether the household is a homeowner. We also explore the effects of reclassification on multiple homeownership, measured by the number

of housing units each household owns. $\alpha_{j}$ and $\rho_{t}$ are community and year (survey wave) fixed 
effects. Reclassification ${ }_{j t}$ is the key variable of interest, which is a dummy variable equal to one if Community $j$ has been reclassified from rural to urban by year $t . X_{i j t}$ is a vector a household-level control variables including household size, age of household head, whether the household head is married, number of children and elderly within the household and whether household has agricultural land. Summary statistics is presented in Table 9. Since we are comparing households in traditional rural villages and reclassified communities, we drop observations from urban communities as well as communities reclassified from urban to rural. Standard errors are clustered at the community level.

Since we exploit the within-community variation in reclassification to distinguish its effect from confounding factors, we are in a difference-in-differences framework. Thus, our identifying assumption would be that in the absence of the reclassification, reclassified communities would have experienced changes in homeownership and other behaviors regarding living conditions and housing demand similar to non-reclassified villages.

One may wonder whether those reclassified communities shared different attributes from traditional rural villages even before they were reclassified, which could cause concerns in our identification strategy. Our data allow us to test and relax this identifying assumption in several ways. First, we offer a formal statistical test by including an indicator for the two years prior to the reclassification in Equation 1. That is, we ask whether reclassified villages diverged in terms of household homeownership even before reclassification. If they do, it suggests that the identifying assumption of our research design is violated. Second, as has been discussed in previous sections, the current standard of rural-urban dichotomy is simply based on land contiguity, independent of the social and economic development of the community. We can empirically test this by taking advantage of our community-level survey panel data. To be more specific, we use community-level demographic and economic variables to predict whether this village would be reclassified within the next survey period (i.e., two years). The dependent variable is an indicator that equals one if a village that had 
never been reclassified was reclassified within the next survey period ${ }^{26}$ Results are shown in Table 10. Column 1 only includes geographic, demographic variables and those proxy for economic development, which could have explanatory power for household homeownership and housing behaviors. The overall R-squared is low (only 0.008) and we fail to reject the hypothesis of the overall insignificance using the joint F-test, though some variables are statistically significant. This significance disappears in specifications which we gradually include county-level fixed effects, year fixed effects and their interaction terms. Across all specifications, the F-statistics are insignificant. As a result, we are assured that observable community-level characteristics that ought to reflect the social and economic development of a community are not correlated with its reclassification status.

Results from Equation 1 using homeownership dummy and number of housing units are shown in Table 11 and 12. Column 1 only includes community fixed effects and year fixed effects while Column 2 includes additionally household-level covariates to increase precision. Results remain unchanged with the coefficients of reclassification dummy, both economically and statistically insignificant, indicating that the community reclassification from rural to urban does not have any impact on household-level homeownership and multiple homeownership. The third column shows that the estimated coefficients remain small in magnitude and insignificance when replacing community fixed effects with household fixed effects. To further mitigate the concern for our identification strategy due to the possibility of differential time trends that would be correlated with the timing of reclassification, in Columns 4 and 5 , we show that the results are robust to controlling for specific time trends more flexibly. In Column 4, we allow communities in different provinces to have different time trends by including province-year fixed effects while Column 5 adopts interacts of all household-level characteristics with each year fixed effect. Our main results for both outcome measures remain economically small and statistically insignificant after introducing several additional

\footnotetext{
${ }^{26}$ Since the first community-level survey was conducted in 2013 , we drop communities that had been reclassified before the year 2013 since we do not have any pre-period information on them. We also drop observations from the 2017 survey since we do not know their rural-urban dichotomy after 2017.
} 
controls for differential time trends.

Table 13 illustrates results including the dummy variable for the two years prior to the reclassification. Adding this indicator makes the omitted category to three or more years prior to treatment, which alters the interpretation of the reclassification dummy. However, the fact that both indicators are small and insignificant reflects that these reclassified community follow similar trend with rural villages in terms of homeownership before reclassification.

One may worry that the control group in our empirical model might not approximate the treatment group well if they fall into different regions of the country. We address this concern in two ways. At the macro level, though provinces along the coastal areas show a somehow larger reclassification rate, provinces with the highest rates are in the central and western areas. Furthermore, neighbouring provinces with similar levels of economic development may show different reclassification behaviors. For example, Shaanxi Province is among the highest reclassification rate, while Shanxi Province, which is to the east of Shaanxi shows the lowest rate of reclassification, although both provinces share similar tradition and culture with similar economic development. Second, at the micro level, in Table 14, we show the baseline results are robust if we drop the observations from provinces that do not have any reclassified community.

Another potential issue of concern is attrition from the CHFS samples. In Table 15 , we run the basic regression used to identify the role of reclassification on homeownership, Equation 1, on attrition. The effect of reclassification on attrition is both small and statistically insignificant. There is therefore no evidence that reclassification would cause different behaviors in terms of attrition from the sample or household moving out of the community.

The rich information on housing from CHFS also allows us to empirically test the reclassification impacts on other housing measures, to see whether there is any housing consmuption increase in quality instead of quantity. Table 16 shows corresponding results. Samples are restricted to households owning at least one housing unit. In Column 1, we regress number of rooms for the current housing unit they live in on the reclassification dummy variable, 
controlling for household-level characteristics, community fixed effects and year fixed effects. The coefficient of reclassification indicator is around 0.4 and insignificant. Next, we use logarithm of housing size as dependent variable in Column 2, the coefficient estimate is negative and also insignificant, indicating that community reclassification does not improve the quality of housing consumption. One character of housing behavior in rural China is that households often build their houses on assigned land (ZhaiJiDi) rather than purchase from the housing markets. In Column 3, we find that the coefficient is around 0 in magnitude.

Starting from the third wave in 2015, the questionnaire also included information regarding housing demand. From both waves in 2015 and 2017, we distinguished their demand as either self-built or purchasing from housing markets. In 2015, the ratio of households that are willing to improve their living conditions by having more houses was similar among all three categories (rural, urban and reclassified), around 20\%. While most urban residents would prefer to purchase apartments, more than half of reclassified villages would like to build housing units themselves. This trend was still obvious in the 2017 wave; this indicates that although noticeable housing demands exist, the majority of households from reclassified communities still prefer to build houses rather than participate in the commercial housing market. In Column 4 of Table 16 , we show that households in reclassified communities are no more willing to participate in more formal housing markets; i.e., they are no more involved in purchasing a unit compared with households in rural villages.

So far, we fail to find any effect of community reclassification from rural to urban on improvement on household housing behavior. Nevertheless, households living in those communities are never regarded as rural citizens in any statistical way. We are interested in the question that in what aspects the reclassification affects households. Did it affect householdlevel income and consumption that might not be revealed from housing behavior? If this urbanization leads to more local job opportunities, this could translate to more welfare gain. To investigate this, we use the household-level survey in all four waves of CHFS. Each survey has a detailed income and consumption module that allows for calculation of different 
sources of income and consumption. Regression results using them as dependent variables are shown in Table 17.

In Column 1, we regress the logarithm of household income per capita on the reclassifi-

cation indicator, household-level covariates as well as the community fixed effects and year fixed effects. Though the coefficient estimates of the reclassification dummy is positive with 0.109 in magnitude, it is not statistically different from zero. In addition, we do not observe a statistically significant effect on overall consumption as well as consumption of non-food items. All results combined, we fail to detect any effect of the community reclassification on improving welfare for the redefined migrant households.

\subsection{Long-Run Reclassification Effects}

One may think that after being reclassified as urban, those communities would follow a differential development trajectory than their rural counterparts. For example, reclassified communities might experience more investments in infrastructures from upper-level governments, which might take years. Thus, it is also important to discover whether there exist any long-run reclassification effects for those reclassified villages.

In Table 18, we show household characteristics in both rural villages and communities reclassified from rural to urban in various years. As the first year we can identify reclassified communities is 2010 and our last wave of survey measures household behaviors in 2017, it has been at least six years for the first cohort of communities since reclassification. However, we fail to discover any noticable difference in all household-level characteristics.

In terms of housing behavior, Figure 5 shows the dynamic reclassification effects on household homeownership and multiple homeownership from a regression framework. The outcome variable is either the homeownership dummy or number of housing units. The key explanatory variables are a series of indicators for 1 or 2 years before reclassification, the year of reclassification, 1 or 2 years after reclassification and 3 or more years after reclassification. The omitted category is 3 or more years before reclassification. We also include community 
and year fixed effects. The red dots indicate the coefficients of estimate while the 95 percent confidence intervals are indicated by lines. In line with the descriptive evidence, we fail to find any long-run effect of reclassification on household housing behaviors.

To summarize, we first descriptively demonstrate that reclassified communities are different from urban communities not only in community characteristics but also in household housing behaviors and demand. In all of these aspects, reclassified areas are identical to rural villages. In addition to this cross-sectional comparison, we empirically show that being reclassified does not have impacts on the development trajectory for the corresponding communities; they still followed the trend that resembles rural villages. Both horizontally and vertically, we fail to detect any difference between reclassified communities and rural villages.

\section{Redefined Migrants, Local Land and Housing Mar- kets}

\subsection{Urban Population as a Determinant of Land Supply}

According to the Constitution, China is under the "Two-Tier Land Tenure System": urban land is owned by the state, and rural land is owned by local collective communes (Li 2018). Local governments have de facto control over city planning and land use.(Fan et al. [2015]). The amount of supplied land is based on city planning, land quota, economic activity, population, income and expenditures, etc. Though there are policies that restrict the ratio of each type (e.g., industrial, commercial, residential) of land supplied, the local government has discretion to some extent on allocating shares of land on different types of use. According to Lichtenberg and Ding 2009 and Fan et al. 2015], after government acquired all land from rural farms and established a land reserve center for management, approximately 20\%-30\% of land reserves were transferred for residential use and offered to the markets, 
mostly through public auctions. Additionally, around 50\% was transferred to investors for industrial use, mostly through negotiation. The price for industrial use was much lower than for residential use. Figure 6 summarizes the land supply for different types of use between 2010 and 2015. During this period, the size of all three types (industrial, commerical and residential) stay quite stable over time. The size of land supply for industrial use is almost a half more than that for residential use, which is then doubled than that for commerical use.

This section focuses on the relationship between urban population and residential land supply. Figure 7 graphically shows a strong positive relationship between land supply and urban population growth at the prefecture level between 2010 and 2015.

Equation 2 tries to find out factors that may be used to determine the local residential land supplies. We adopt a fixed-effects panel data model using prefecture-year observations for all prefectures which we can obtain urban population data from 2010-2015. Specifically, the regression equation is:

$$
\text { Residential_Land }_{j, t}=\alpha_{j}+\rho_{t}+\beta \text { Urban_Population }_{j, t-1}+X_{j, t-1}^{\prime} \gamma+\epsilon_{j, t}
$$

where Residential_Land Lit, $_{\text {is }}$ the total land for residential use in prefecture $j$ as of year $t$ while Urban_Population ${ }_{j, t-1}$ is the one-year lagged measure for the urban population in prefecture $j$. Both variables are logged so the coefficient $\beta$ can be interpreted as the elasticity of residential land with respect to urban population. We control for the prefecture fixed effects and year fixed effects as well as a list of one-year lagged prefecture-level time-varying covariates including the prefecture area, per capita GDP, per capita fiscal income, per capita size of paved roads and green spaces ${ }^{27}$ Standard errors are clustered at the prefecture level.

Regression results are shown in Table 19, Column 1 presents the results only controlling for the prefecture and year fixed effects. The elasticity of residential land with respect to urban population is large in magnitude and statistically significant. A one percent increase

\footnotetext{
${ }^{27}$ Data on GDP and fiscal income at the prefecture level come from the China City Statistical Yearbooks. Since the yearbooks do not include information on prefecture-level autonomous regions, we exclude those observations in the regression.
} 
in urban population is associated with 0.50 percent increase in residential land in the next year, indicating that total urban population growth is a strong predictor of residential land supply. In Column 2, we add the lagged prefecture-level covariates as in our baseline specification in Equation 2, the coefficient increases to 0.60 and still highly significant. In the next column, we further include the region-by-year fixed effect: ${ }^{28}$ to account for potential differential changes in different regions due to the central government policies in favor of less developed central and western provinces, the coefficient is almost unchanged. Lastly, in Column 4, we allow each prefecture to have its own linear trend; again, the elasticity is high both economically and statistically. As expected and in line with the urban planning literature in China, the growth in urban population is a key determinant on the amount of residential land supplied within the prefecture.

We can also test the elasticity of local land supply with respect to the total number of residents instead of the urban population only. Columns 1 and 2 in Table 20 show that the coefficients are similar but imprecisely estimated. Administratively, an alternative way to measure population at the prefecture level is through the Hukou registration system. The local department of public safety would annually document the total number of people whose Hukou registration is within the prefecture. However, in the last two columns of Table 20 , results show that they are quite sensitive to different specifications while the coefficients are statistically insignificant and even negative.

In addition, it is interesting to explore whether this elasticity is heterogeneous across prefectures with different attributes. While it is plausible to categorize different prefectures by different dimensions, we would divide prefectures into three tiers, which has been widely used officially and unofficially. To be more specific, we are dealing with this potential heterogeneity between the second-tier and third-tier cities ${ }^{29}$ Second-tier cities consist of most

\footnotetext{
${ }^{28}$ We divide the country into three regions: East, Central and West.

${ }^{29}$ The first-tier cities include Beijing, Shanghai, Guangzhou and Shenzhen, two provincial-level municipalities and two prefecture-level cities in the coastal Guangdong province. These four cities have a large urban population and enjoy a large wave of immigrants, with very different policies in the land and housing markets.
} 
provincial capitals and municipalities that are local economic and political centers while the remaining prefectures are considered the third-tier. Table 21 shows the results for prefectures from these two tiers. Unlike Tier 3 cities which are relatively less developed, for tier 2 prefectures, residential land supply is inelastic to urban population growth. The different sensitivities of land supply to population growth might reflect the different weights of urban population in the urban planning process. Since the second-tier prefectures are usually provincial capitals or local economic centers, they tend to attract population from nearby less developed third-tier prefectures on a fixed bases. As a result, urban population is less predictive of land supply in these prefectures.

\subsection{Redefined Migrants and Local Residential Land Supply}

The fact that urban population growth is a strong determinant of local land supply for residential use is expected. However, different prefectures might have different compositions of urban population growth. For example, in metropolises, migration both from rural areas within the prefecture and from outside the prefecture might account for the majority of urban population growth while in some small and remote prefectures redefined migrants might dominate. Since redefined migrants are similar to rural residents, the total urban population increase net of the size of redefined migrants should be of more importance. This section studies the relative importance of this "net urban population growth" and redefined migrants. A regression equation is adopted as follows:

$$
y_{c, p, \Delta t}=\beta_{0}+\beta_{1} N e t \_U P G_{c, p, \Delta t}+\beta_{2} \text { Redefined }_{c, p, \Delta t}+X_{c, p, t_{0}}^{\prime} \gamma+\phi_{p}+\epsilon_{c, p, \Delta t}
$$

where $y_{c, p, \Delta t}$ measures the land supply of prefecture $c$ in province $p$ during time period $\Delta t ; N_{e} U_{-} P G_{c, p, \Delta t}$ and Redefined $d_{c, p, \Delta t}$ measure the net urban population growth and the size of redefined migrants respectively. $X_{c, p, t_{0}}$ is a list of control variables similar to those in Equation 2 but they are measured as of the base year (2010). We also add the level of 
residential land as a control variable. $\phi_{p}$ controls for province fixed effects ${ }^{30}$ Standard errors are clustered at the province level.

Table 22 shows the results of the relationship between different sources of urban population growth and residential land supply. Column 1 only includes the total urban population growth. Similar to our results using the prefecture-level panel data set, the coefficient which can be interpreted as elasticity is 0.61 , large and highly significantly different from zero, implying a strong relationship between urban population growth and residential land supply. In the next two columns, we add our measure of net urban population growth and redefined migrants respectively. Both measures are of similar size and significant. In the last column, we include both measures in one regression. Both coefficients are qualitatively and quantitatively unchanged. While this result is suggestive, it shows that the elasticity of residential land supply with respect urban population from redefined migrants is almost at large as predictive as that with respect to net urban population growth, the group of which is thought to have real demand for urban housing markets.

In addition, we divide the cities into different tiers and estimate Equation 3 separately. While residential land supply is inelastic to urban population growth in Tier-2 cities, it is very sensitive to both net urban population growth and redefined migrants in smaller Tier-3 cities (Table 23), consistent with what we find from the panel data regressions.

\subsection{Redefined Migrants and City Nighttime Light}

An alternative way to illustrate that redefined migrants exhibit differing impacts from relocating migrants on urbanization process is to look at their effects on development in both economic activities and land use. One appealing way to measure the economic development in the recent literature is to look at the change of nighttime light Donaldson and Storeygard [2016]). Measures using light data at the prefecture level are particularly fit into our setting not only because they are good proxies for economic growth (Henderson et al. [2012]),

\footnotetext{
${ }^{30}$ For the four province-level municipalities, Beijing, Tianjin, Shanghai and Chongqing, the results are virtually unchanged if these four observations are dropped.
} 
but also in that they partly address the downside of using GDP growth within the entire boundary of prefecture cities since in China they normally incorporate substantial rural areas (Dingel et al. [2019]).

Data on the nighttime light are from the U.S. National Defense Meteorological Satellite Program (DMSP). As with the empirical literature that studies using the nighttime light data, average digital number at the prefeture-year level between 2010 and 2013 is obtained. We adopt a regression equation similar to Equation 3, with the difference of the logarithm of city nighttime light between 2010 and 2013 as the dependent variable. Consequently, different sources of urban population growth between 2010 and 2013 are used as key explanatory variables 31

Results are shown in Table 24. In the first column, we regress the difference of the logarithm of city nighttime light between 2010 and 2013 on the size of total urban population growth at the prefecture level and find an economically and significantly large effect. Increasing the net urban population growth by ten percent would lead to an around $0.35 \%$ increase in the prefecture average night light. However, in the next two columns, such effects of net urban population growth as well as redefined migrants are of different sizes and levels of significance, indicating that only the net urban population growth contributes to the city nighttime economic activities.

\subsection{Surplus Index and Housing Vacancy}

Urban population growth is one of the primary predictors for local governments' urban land supply. More importantly, as shown previously, this relationship is as strong for the size of redefined migrants as for the net urban population growth, with the former having little housing demand in the local housing markets. To quantify this extra supply casued by redefined migrants, we construct an index for every prefecture measuring the degree of surplus supply. Specifically, we regress land supply for residential use on the net urban

\footnotetext{
${ }^{31}$ Here we do not use lags of the explanatory variables since nighttime light reflects the contemporaneity of economic development as well as population mobility.
} 
population growth to predict the fitted amount of residential land supply ${ }^{32}$ The index is the ratio between actual residential land supply and this predicted value. The higher the ratio, the more excess supply the city has provided. Put differently, the surplus index is higher when a prefecture supplies excess residential land for the net urban population growth. In Figure 8, we show a negative relationship between this index and the average housing price change for almost 100 major prefecture-level cities in China from 2010 to 20153

In order to link the prefecture-level surplus index with the household-level vacant housing units, we combine this surplus index and findings from CHFS data. Empirically, the regression equation is as follows:

$$
\text { vacant_house }_{h, p, l}=\beta_{0}+\beta_{1} * \text { Surplus_Index } x_{p, l}+X_{h, p, l} \gamma+\phi_{l}
$$

where vacant_house $_{h, p, l}$ is our measure of housing vacant information for household $h$ that has at least one housing unit in urban areas in prefecture $p$ with tier $l$; it is either a dummy variable taking the value of 1 if the household has at least one unit of vacant house or the number of vacant houses. Surplus_Index $x_{p, l}$ is the prefecture level surplus index we constructed. $X_{h, p, l}$ is a vector of variables including household size, Hukou status, age and education level for household head, household income and expenditures, whether a household has vehicles. City-tier dummy variables are also included. Since the key variable of interest, Surplus_Index $x_{p, l}$ is a generated variable, we also present results using bootstrapped standard errors with 100 repetitions.

Results are shown in Table 25. For the dummy variable, we use Probit model and report marginal effects. For the number of housing units variable, a Poisson regression is adopted. The results, for all specifications, are similar and quite robust. The prefecture-level surplus index we constructed is positively related to both our measures of household-level vacant housing units, and is significant at the $5 \%$ level. In cities with a larger surplus index (where

\footnotetext{
${ }^{32}$ The regression equation is similar to Equation 3 , but does not control for province fixed effects.

${ }^{33}$ Data for housing price at the prefecture level are from China Residential House Price Index (HPI-100) published monthly by the China Index Academy.
} 
there is a higher excess supply of residential land), households are more likely to have vacant housing units.

\subsection{Revisiting the Vacant Housing Puzzle}

Summarizing what we have discussed in previous sections, a large wave of newly added households in urban areas exist simply because the areas they live in have been reclassified from rural to urban. These redefined migrants comprised $34 \%$ of total urban population growth from 2010 to 2015; they had little demand in urban housing markets since they "bring" their own housing units into urban areas. To quantify its size, we simply combine our estimated size of redefined migrants with information regarding their living conditions from descriptive evidence found in CHFS datasets. Results show that between 2010 to 2015, redefined migrants account for 33.83 million, which is approximately 8.93 million households from reclassified communities (The family size of households in reclassified community is 3.79, shown in Table 8). Around $94 \%$ of these households have their own housing units. As a result, they brought around 8.39 million housing units into urban areas, given all these houses are located within these reclassified communities. Combining results from Chen and Song [2014 by employing similar assumptions, from 2000 to 2010, these reclassified migrants brought around 30.4 million housing units into urban areas. In total, during the first 15 years of this new millennium, the size of newly added urban households from redefined migrants brought around 38.79 million housing units into urban areas, accounting for nearly $80 \%$ of total number of vacant housing units estimated by CHFS in 2014. This result provides evidence in favor of the high vacancy rate found by CHFS. In fact, when comparing the added urban housing units and urban households, the size of redefined migrants has been taken into account in calculating the increment of newly added urban households but the housing units brought by these redefined migrants are not taken into account in considering the increments of newly added urban housing units. This mismatch due to neglecting the group of redefined migrants causes excess supply which in turn leads to large numbers of 
vacant housing units in urban China.

\section{Conclusions}

Accompanied by rapid economic development, in 2018 China's urbanization rate reached $60 \%$. A large wave of the population migrated and settled in urban areas, causing a consistent demand for housing. As a result, urbanization is considered to be an important factor for the enlarged urban housing demand. In this paper, however, we find that a large share of new urban residents during the first half of the 2010s actually came from communities that were reclassified from rural to urban. Relying on the rural-urban division codes which are issued by the National Bureau of Statistics every year, we estimate that around $34 \%$ of the total urban population growth from 2010 to 2015 resulted from rural-urban dichotomy reclassification.

Further exploration of the demographic and economic characteristics of reclassified communities and redefined migrants finds empirical evidence that these communities are far less urbanized than those in urban areas; most households still live in traditional rural houses and have little demand to participate in local housing markets. We then use prefecture-level land supply data and our measures of urban population growth to empirically estimate the relationship between local land supply and different types of urban population growth. Our results show that the elasticity of the size of redefined migrants is as large as that of net urban population growth. If this is the case, we can anticipate large amounts of surplus housing units, especially in cities with large sizes of redefined migrants. All of this evidence supports

a recent finding from the China Household Finance Survey that the housing vacancy rate in urban areas is over $20 \%$. 


\section{References}

Kam Wing Chan and Ying Hu. Urbanization in China in the 1990s: New definition, different series, and revised trends. China Review, pages 49-71, 2003.

Qin Chen and Zheng Song. Accounting for China's urbanization. China Economic Review, 30:485-494, 2014.

Peter Christensen and Gordon C. McCord. Geographic determinants of China's urbanization. Regional Science and Urban Economics, 59:90-102, 2016.

Xiangzheng Deng, Jikun Huang, Scott Rozelle, and Emi Uchida. Growth, population and industrialization, and urban land expansion of China. Journal of Urban Economics, 63 (1):96-115, 2008.

Jonathan I. Dingel, Antonio Miscio, and Donald R. Davis. Cities, lights, and skills in developing economies. Journal of Urban Economics, 2019.

Dave Donaldson and Adam Storeygard. The view from above: Applications of satellite data in economics. Journal of Economic Perspectives, 30(4):171-98, 2016.

Jianyong Fan, Jiawei Mo, and Jipeng Zhang. Housing models and urbanization in China: Empirical research from the perspective of land supply. Social Sciences in China, 4:44-63, 2015.

Edward Glaeser and J. Vernon Henderson. Urban economics for the developing world: An introduction. Journal of Urban Economics, 98:1-5, 2017.

J. Vernon Henderson, John Quigley, and Edwin Lim. Urbanization in China: Policy issues and options. Unpublished manuscript, Brown University, 2009.

J. Vernon Henderson, Adam Storeygard, and David N. Weil. Measuring economic growth from outer space. American Economic Review, 102(2):994-1028, 2012. 
Xuan Li. The political cycle in China's primary land market. Working Paper, 2018.

Xuesong Li and Yanyan Huang. Rising housing price, multi-suite decision and household savings rate in urban China. Economic Research Journal, 9:100-113, 2015.

Erik Lichtenberg and Chengri Ding. Local officials as land developers: Urban spatial expansion in China. Journal of Urban Economics, 66(1):57-64, 2009.

United Nations. World urbanization prospects. Technical Report, 2018.

National Bureau of Statistics. Guidelines for statistically classifying rural and urban areas (for trial implementation). 1999.

National Bureau of Statistics. Standards for statistically classifying rural and urban areas. 2008.

UNICEF. The state of the world's children 2012: Children in an urban world. Technical Report, 2012.

Fang Wang. Composition of population growth between the fourth and fifth census in urban China. Population Research, 28(3):60-67, 2004.

Shing-Yi Wang. State misallocation and housing prices: theory and evidence from China. American Economic Review, 101(5):2081-2107, 2011.

Hongwen Yu. Traits of population situation seen through 2000 census. Population Research, 25(4):12-18, 2001.

Jipeng Zhang, Jianyong Fan, and Jiawei Mo. Government intervention, land market, and urban development: Evidence from Chinese cities. Economic Inquiry, 55(1):115-136, 2017.

Kevin Honglin Zhang and Shunfeng Song. Rural-urban migration and urbanization in China: Evidence from time-series and cross-section analyses. China Economic Review, 14(4):386400, 2003. 
Siqi Zheng and Matthew E. Kahn. Land and residential property markets in a booming economy: New evidence from Beijing. Journal of Urban Economics, 63(2):743-757, 2008. 


\section{Figures}

Figure 1: Urban Household Growth and Housing Supply

\section{Thousands Urban Household Growth and Housing Supply}

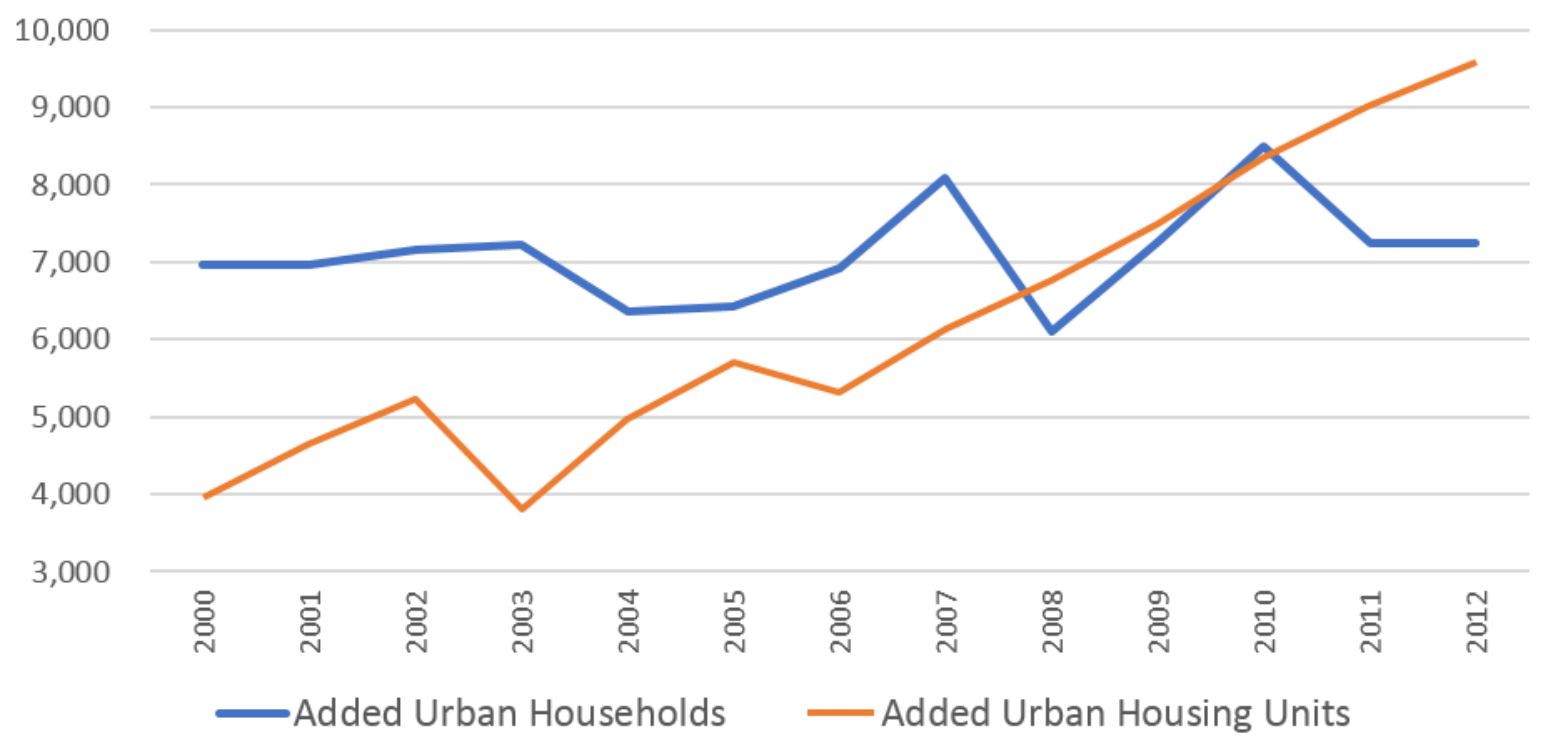

Note: Data on urban population and average urban household size are from the National Bureau of Statistics. For added urban households in year $t$, it is calculated as (total urban population in year $t$ - total urban population in year $t$-1) / average urban household size in year $t$. Data on size of added housing units are from the 2014 China Statistical Yearbook. For added housing units in year $t$, it is calculated as (the newly built housing size in urban areas in year $t$ / average size per housing unit) - estimated demolished housing units in year $t$. We assume the average size per housing unit is 90 square meters. Annual demolished housing units are estimated from the 2013 wave of China Household Finance Survey. 
Figure 2: Screenshots of Community ID and Rural-Urban Division Codes

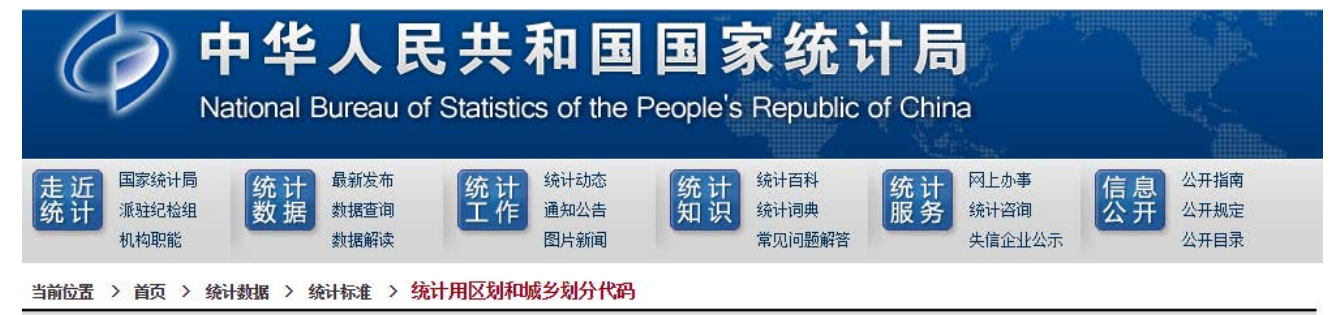

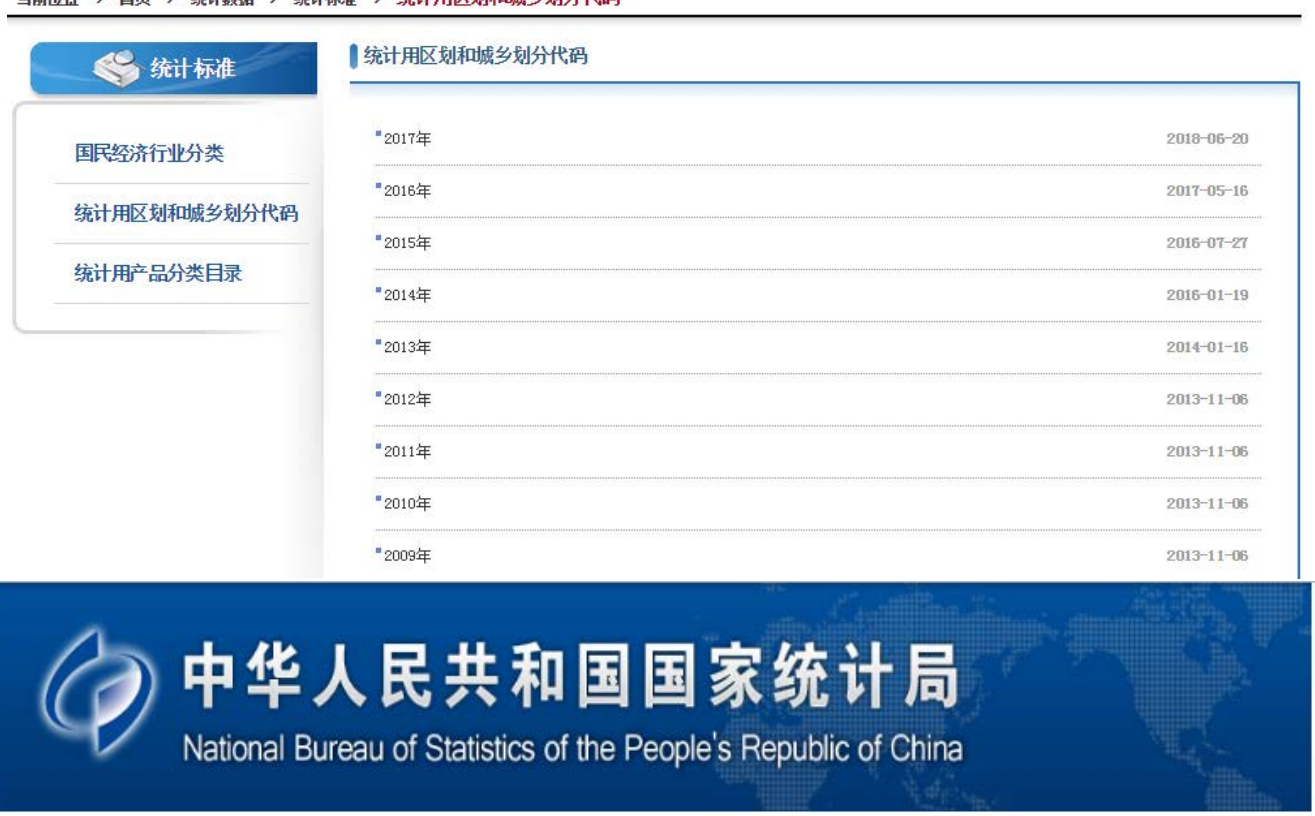

\begin{tabular}{|c|c|c|}
\hline 代码 & 域乡分类 & 各称 \\
\hline 110101001001 & 111 & 名福巷社区居秀会 \\
\hline 110101001002 & 111 & 银闸社区居委会 \\
\hline 110101001005 & 111 & 东厂社区居秉会 \\
\hline 110101001006 & 111 & 智德社区居委会 \\
\hline 110101001007 & 111 & 南池子社区居秀会 \\
\hline 110101001008 & 111 & 董图市社区居季会 \\
\hline 110101001009 & 111 & 灯市口社区居秀会 \\
\hline 110101001010 & 111 & 正义路社区居秀会 \\
\hline 110101001011 & 111 & 甘雨社区居秀会 \\
\hline 110101001013 & 111 & 台基厂社区居委会 \\
\hline 110101001014 & 111 & 韶九社区居委会 \\
\hline 110101001015 & 111 & 王府井社区居秀会 \\
\hline
\end{tabular}

版权所有 : 中华人民共和国国家统计局 京CP备05034670号

地址 : 北京市西城区月坛南街57号 ( 100826 ) 
Figure 3: Population between CHFS Community Samples and 2010 Census

\section{Average Rural Community Population CHFS and 2010 Census}
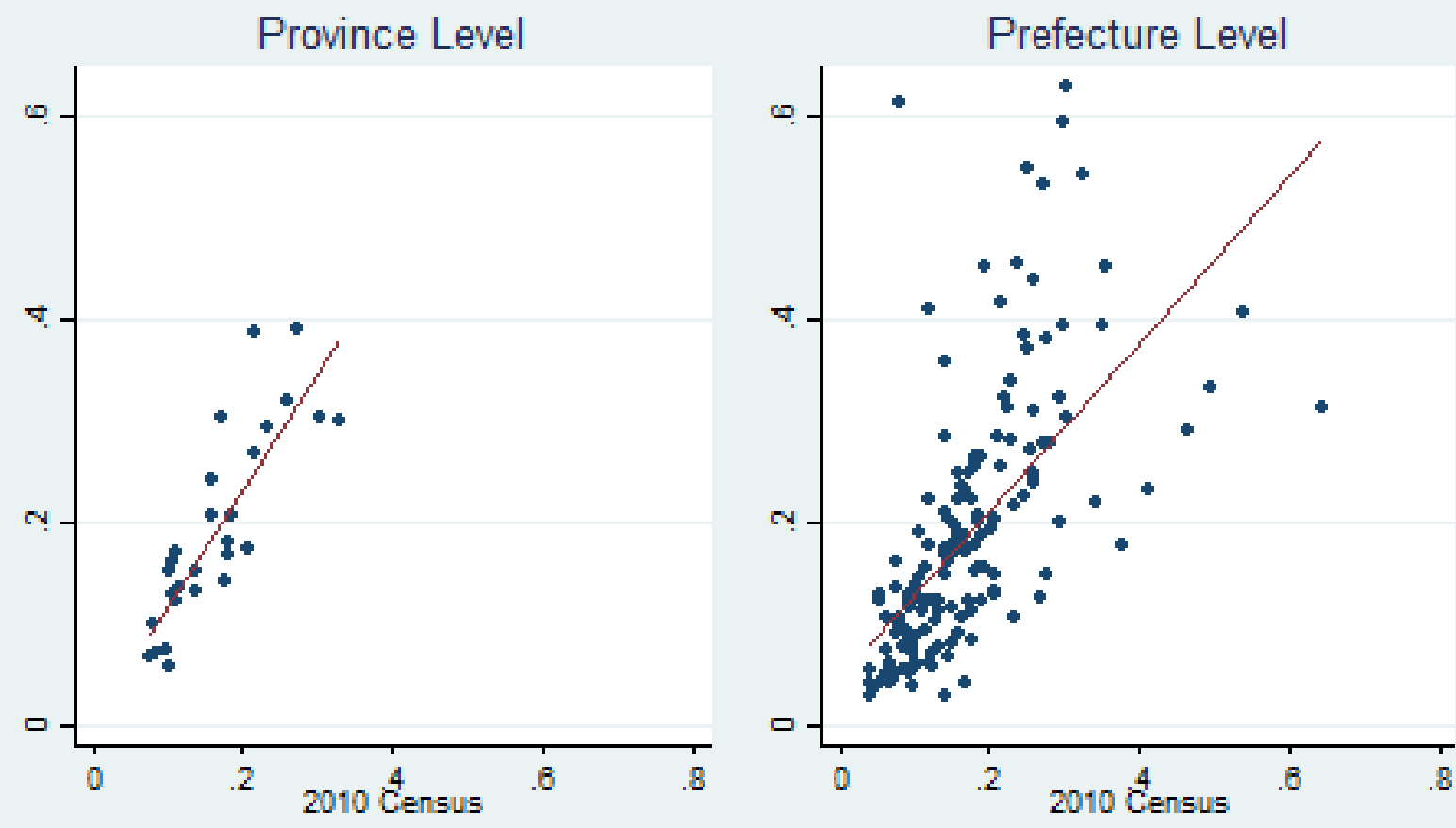

- Number of Residents —_ Fitted Lin

- Number of Residents — Fitted Ling

Note: Data for average rural community population measured in the horizontal axis come from the 2010 Census and the total number of rural communities in 2010 from the National Bureau of Statistics. Data for average rural community population measured in ther vertical axis come from the 2013,2015 and 2017 waves of community survey from China Household Finance Survey. 
Figure 4: Distributions for Urban Population Growth across Prefectures

\section{Distributions for Urban Population Growth 2010-2015}
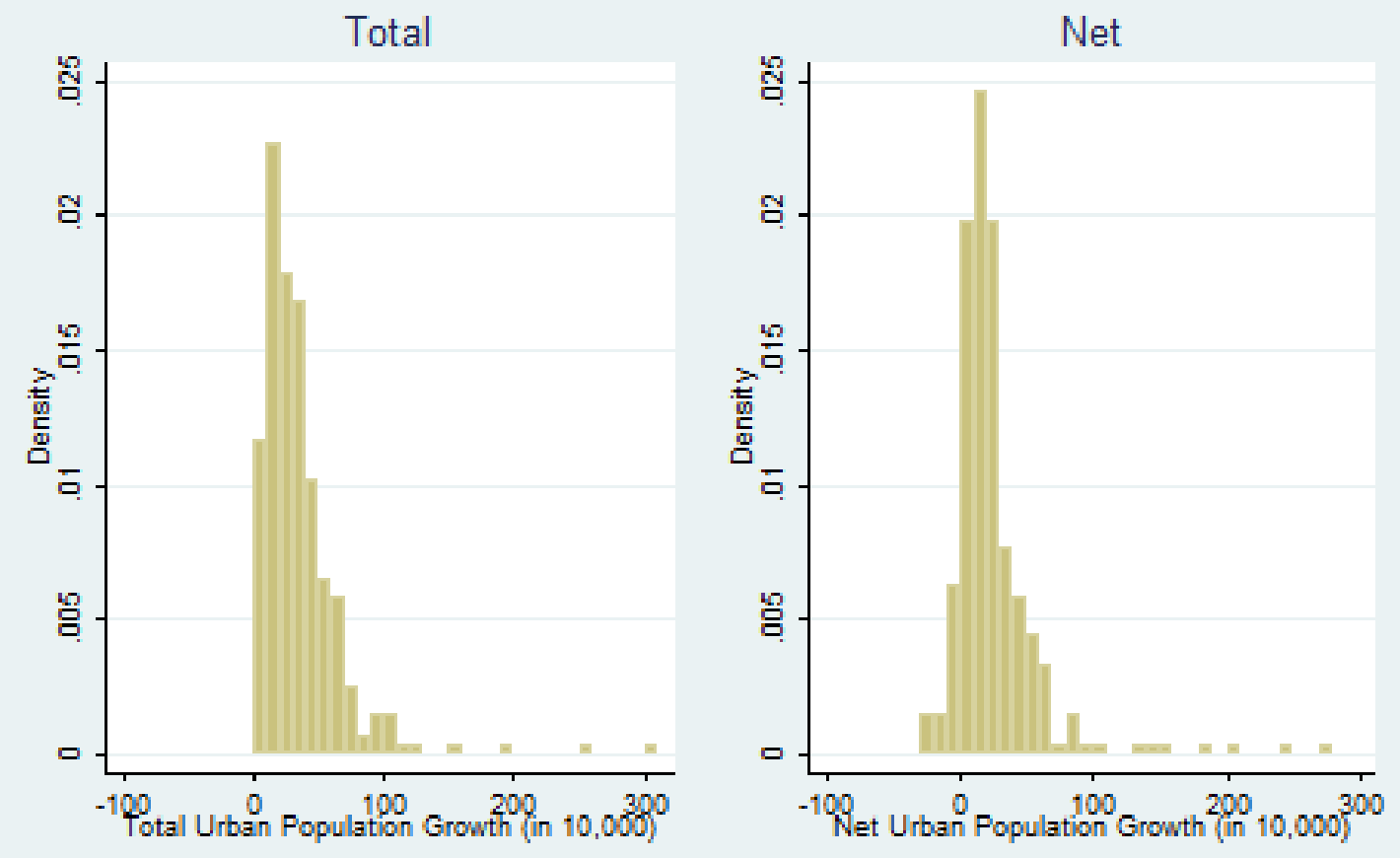

Note: Both total and net urban population growth are measured in 10,000. Total urban population growth is the total urban population growth between 2010 and 2015 while net urban population growth is total urban population growth net of the size of redefined migrants. 
Figure 5: Dynamic Reclassification Effects
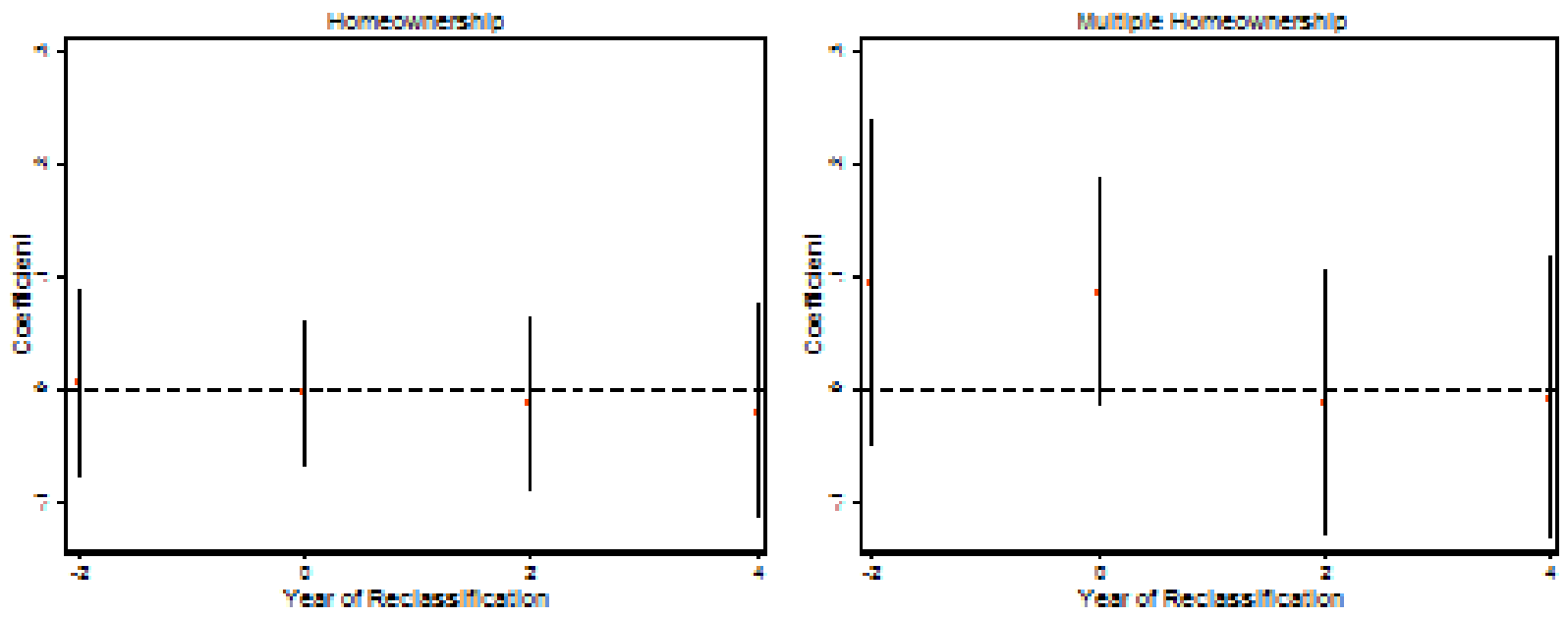

Note: The graph shows the dynamic reclassification effects on household homeownership and multiple homeownership in a regression framework. The outcome variable is either the homeownership dummy or number of housing units. The key explanatory variables are a series of indicators for 1 or 2 years before reclassification, the year of reclassification, 1 or 2 years after reclassification and 3 or more years after reclassification. The omitted category is 3 or more years before reclassification. We also include community and year fixed effects. Standard errors are clustered at the community level. The 95 percent confidence intervals are indicated by lines. 
Figure 6: Land Supply for Different Uses (2010-2015)

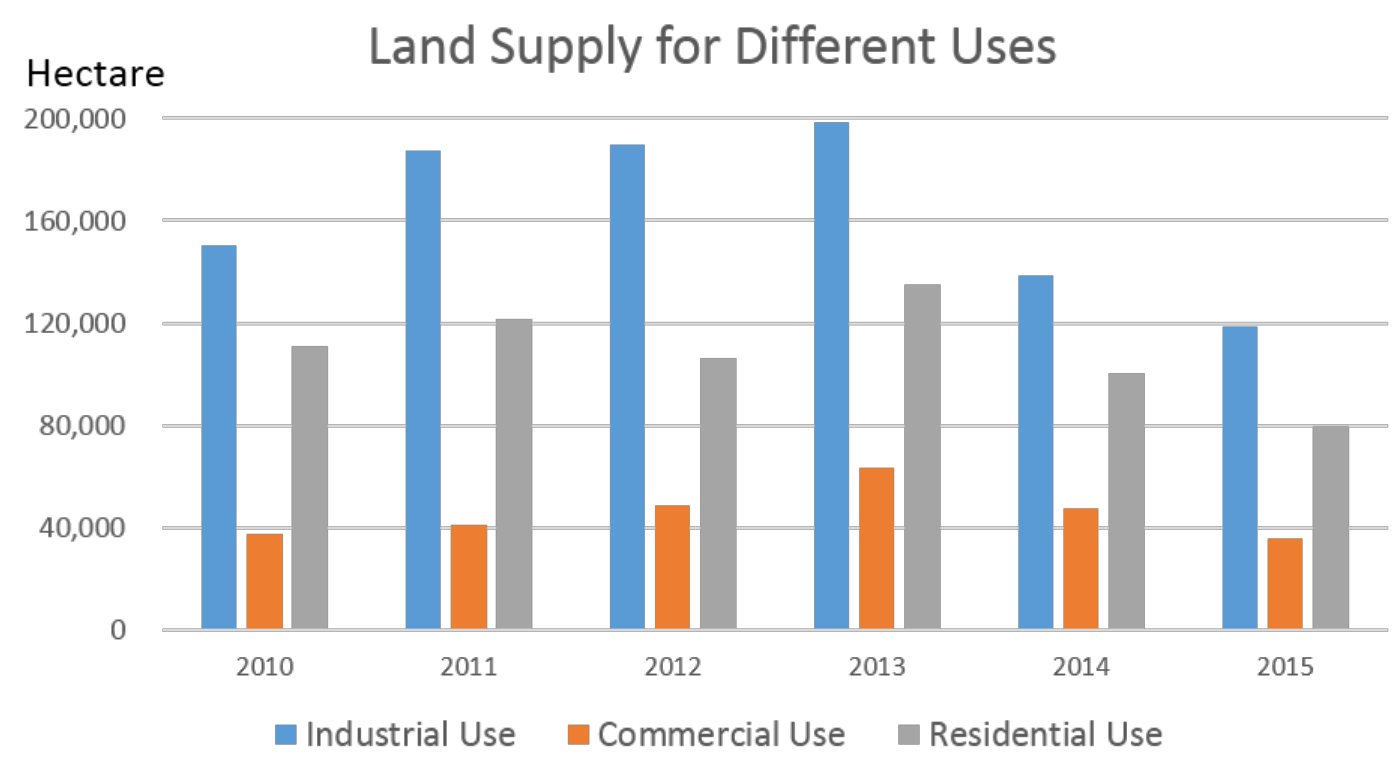

Note: Data for land supplied at the prefecture level are from the the China Urban Construction Statistical Yearbooks. In order to for the aggregated number to be comparable across years, we keep prefectures with non-missing values at all years. 
Figure 7: Urban Population Growth and Total Land Supply

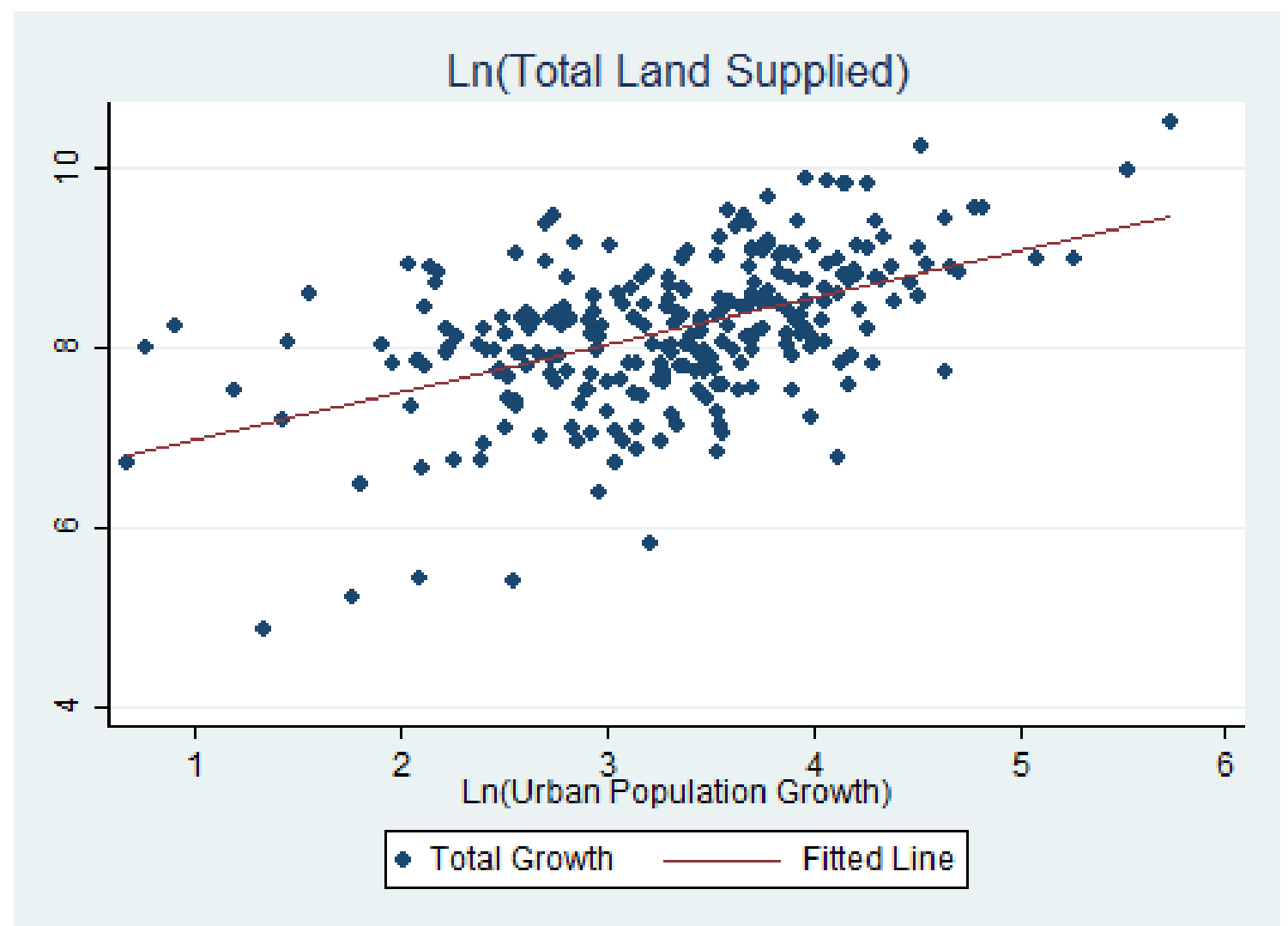

Note: Data for total land supplied at the prefecture level are from the the China Urban Construction Statistical Yearbooks. Urban population growth is measured in 10,000 and the data come from 2010 population census and provincial- and prefecture-level statistical yearbooks. 
Figure 8: Surplus Index and Housing Price Change

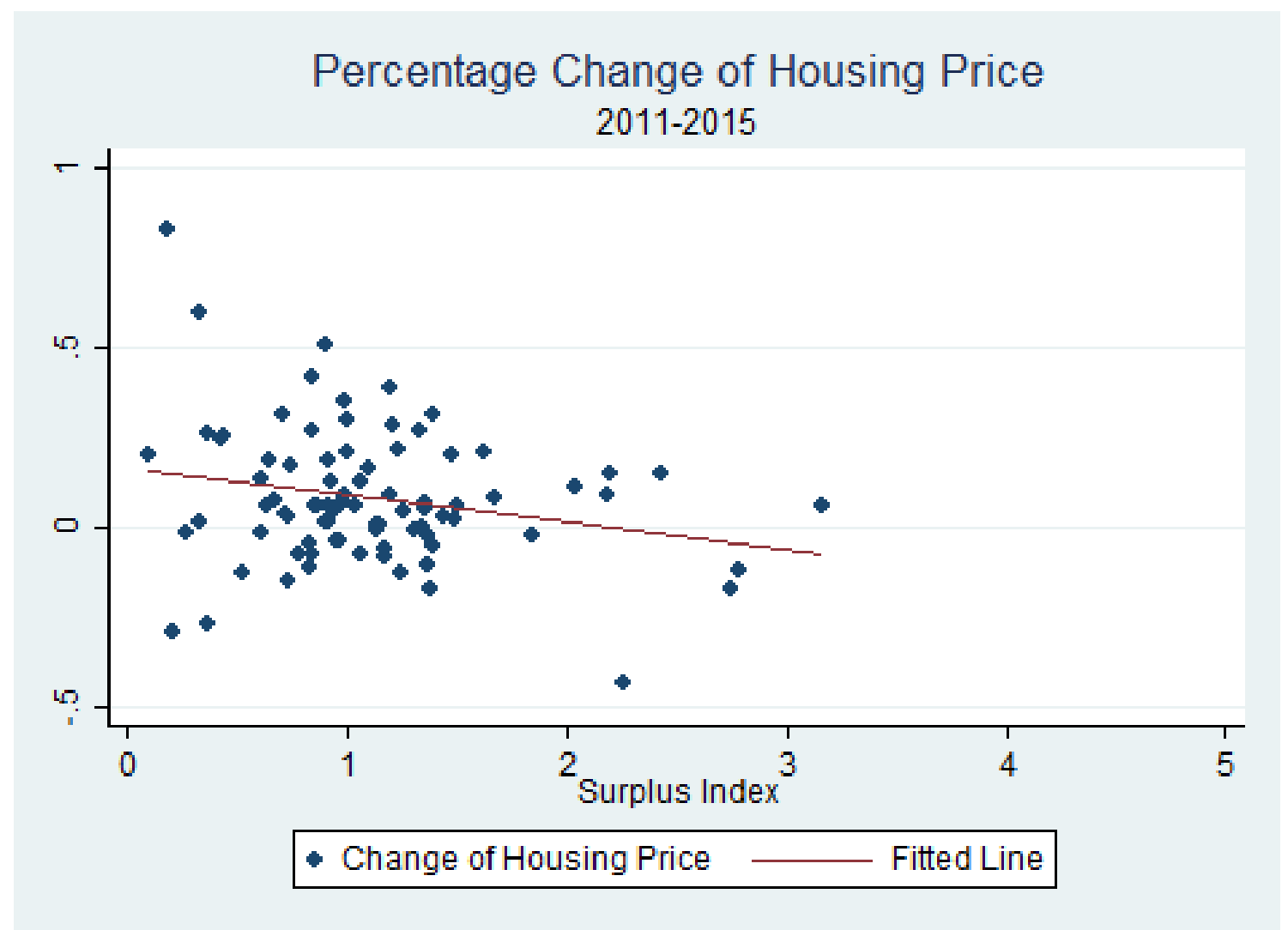

Note: Data of housing price at the prefecture level are from China Residential House Price Index (HPI100) published monthly by the China Index Academy. We calculate the percentage change of housing price as (average housing price in December 2015 - average housing price in December 2010) / average housing price in December 2010. See Section 4 for detailed information on how to calculate the surplus index. 


\section{Tables}

Table 1: International Comparisons for the Housing Vacancy Rate

\begin{tabular}{llll}
\hline \hline & Year & Vacancy Rate & Source \\
\hline Australia & 2017 & $2.5 \%^{\mathrm{a}}$ & SQM Research \\
\hline Brazil & 2012 & $11.3 \%$ & Ministério das Cidades \\
\hline China (Urban) & 2017 & $21.4 \%$ & China Household Finance Survey \\
\hline Germany & 2011 & $4.5 \%^{\mathrm{b}}$ & Statistisches Bundesamt \\
\hline Hong Kong & 2013 & $4.1 \%^{\mathrm{c}}$ & Hong Kong Property Review \\
\hline Japan & 2013 & $13.5 \%$ & Statistic Bureau of Japan \\
\hline Mexico & 2010 & $14.2 \%^{\mathrm{d}}$ & INEGI 2010 Population and Housing Census \\
\hline Singapore & 2014 & $7.8 \%^{\mathrm{e}}$ & Yearbook of Statistics Singapore \\
\hline United States & 2014 & $13.4 \%^{\mathrm{f}}$ & United States Census Bureau \\
\hline \hline
\end{tabular}

a This number refers to the rental vacancy rate, conducted monthly by a private Australian research company.

b According to the micro census, a vacant property is defined as a housing unit in which no interview partner was found even after multiple visits.

${ }^{c}$ This number refers to Vacant housing units at the end of the year as a percentage of total housing stock.

d A vacant home is defined as dwelling that is offered for sale or rent, rented or sold awaiting occupancy, or held off market for other reasons. This excludes housing for temporal use.

e This number refers to the percentage of the existing stock that is vacant. Vacant Houses are defined as vacant units/space that are/is not physically occupied.

$\mathrm{f}$ This number refers to the share of vacant housing units as of all housing units. Vacant housing units include both year-round vacant units and seasonal vacant units. 


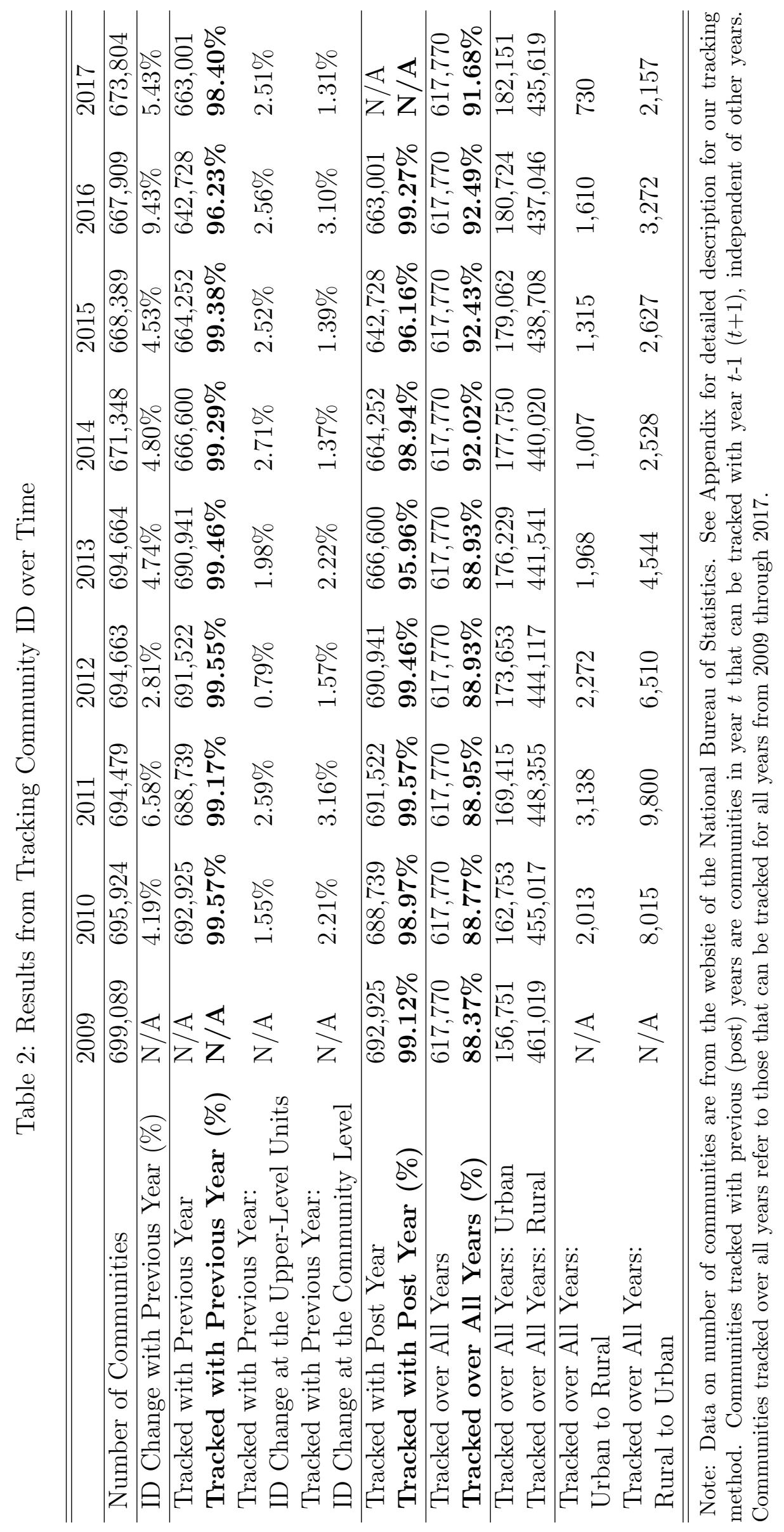


Table 3: Results from Tracking Communities: 2010-2015

\begin{tabular}{lcc}
\hline \hline & 2010 & 2015 \\
\hline Number of Communities & 695,924 & 668,389 \\
\hline Tracked Communities & 649,182 & 649,182 \\
\hline Tracked Communities: Urban & 168,576 & 186,388 \\
\hline Tracked Communities: Rural & 480,606 & 462,794 \\
\hline Tracked Communities: Rural to Urban & 27,795 \\
\hline Tracked Communities: Urban to Rural & 9,983 \\
\hline Tracked Communities: Percentage of 2010 Rural & $\mathbf{3 . 7 1 \%}$ \\
\hline \hline
\end{tabular}

Note: Data on number of communities are from the website of the National Bureau of Statistics. See Appendix A for detailed description for our tracking strategy. Tracked communities as a percentage of 2010 rural villages are calculated as (the number of tracked communities from rural to urban - the number of tracked communities from urban to rural) / the number of tracked rural communities in year 2010. 
Table 4: Summary of CHFS Community Survey

\begin{tabular}{llrrrr}
\hline \hline & & 2013 & 2015 & 2017 & Pooled \\
\hline & No. Provinces & 29 & 29 & 29 & \\
& No. Prefectures & 163 & 170 & 170 & \\
& No. Communities & 1,021 & 1,362 & 1,417 & \\
\hline \multirow{2}{*}{ Urban } & No. Communitites & 505 & 676 & 694 & 1,875 \\
& Average Population & 7,596 & 7,215 & 7,187 & 7,308 \\
\hline \multirow{2}{*}{ Rural } & No. Communitites & 388 & 524 & 550 & 1,462 \\
& Average Population & 2,061 & 1,926 & 1,912 & 1,956 \\
\hline \multirow{2}{*}{ Rural to Urban } & No. Communitites & 22 & 37 & 42 & 101 \\
& Average Population & 2,277 & 2,110 & 2,070 & 2,130 \\
\hline \multirow{2}{*}{ Urban to Rural } & No. Communitites & 12 & 14 & 15 & 41 \\
& Average Population & 2,268 & 2,003 & 1,837 & 2,020 \\
\hline \hline
\end{tabular}

Note: Data are from the Community Survey $(2013,2015,2017)$ of the China Household Finance Survey. 
Table 5: Redefined Migrants by Province by Year

\begin{tabular}{|c|c|c|c|c|c|}
\hline & & 2012 & 2013 & 2014 & 2015 \\
\hline \multirow[b]{2}{*}{ Anhui } & Redefined & 1005 & 432 & 157 & 150 \\
\hline & Total & 1100 & 1020 & 1040 & 1130 \\
\hline \multirow{2}{*}{ Beijing } & Redefined & 27 & -23 & -4 & -2 \\
\hline & Total & 440 & 410 & 330 & 190 \\
\hline \multirow{2}{*}{ Chongqing } & Redefined & 170 & -27 & -62 & 51 \\
\hline & Total & 720 & 550 & 500 & 550 \\
\hline \multirow{2}{*}{ Fujian } & Redefined & 472 & 424 & 287 & 125 \\
\hline & Total & 730 & 590 & 590 & 510 \\
\hline \multirow{2}{*}{ Gansu } & Redefined & 122 & 322 & 138 & 252 \\
\hline & Total & 460 & 370 & 440 & 430 \\
\hline \multirow{2}{*}{ Guangdong } & Redefined & -644 & -167 & 86 & 109 \\
\hline & Total & 1540 & 720 & 800 & 1620 \\
\hline \multirow{2}{*}{ Guangxi } & Redefined & 206 & 165 & 89 & 128 \\
\hline & Total & 960 & 770 & 720 & 700 \\
\hline \multirow{2}{*}{ Guizhou } & Redefined & 1312 & 289 & 809 & 238 \\
\hline & Total & 560 & 560 & 790 & 790 \\
\hline \multirow{2}{*}{ Hainan } & Redefined & 0 & 1 & -15 & -2 \\
\hline & Total & 140 & 150 & 140 & 160 \\
\hline \multirow[b]{2}{*}{ Hebei } & Redefined & -850 & -140 & 238 & 262 \\
\hline & Total & 1090 & 1170 & 1140 & 1690 \\
\hline \multirow{2}{*}{ Heilongjiang } & Redefined & 17 & 40 & 33 & 28 \\
\hline & Total & 160 & 190 & 230 & 170 \\
\hline \multirow{2}{*}{ Henan } & Redefined & 731 & 603 & 98 & -518 \\
\hline & Total & 1820 & 1320 & 1420 & 1760 \\
\hline \multirow{2}{*}{ Hubei } & Redefined & 103 & 326 & 173 & 86 \\
\hline & Total & 1080 & 690 & 770 & 890 \\
\hline \multirow{2}{*}{ Hunan } & Redefined & 1211 & 352 & 313 & 727 \\
\hline & Total & 1220 & 1120 & 1110 & 1320 \\
\hline \multirow{2}{*}{ Inner Mongolia } & Redefined & 41 & 8 & 13 & 12 \\
\hline & Total & 330 & 280 & 250 & 230 \\
\hline & Redefined & 1230 & 303 & 428 & 273 \\
\hline Jiangsu & Total & 1010 & 1000 & 1010 & 1150 \\
\hline & Redefined & 267 & 329 & 218 & 88 \\
\hline Jiangxı & Total & 890 & 700 & 710 & 760 \\
\hline & Redefined & -36 & -42 & 29 & -1 \\
\hline Jilin & Total & 90 & 140 & 180 & 140 \\
\hline & Redefined & 75 & 93 & -441 & -136 \\
\hline Liaoning & Total & 740 & 360 & 270 & 80 \\
\hline & Redefined & 3 & 2 & -30 & -24 \\
\hline Ningxia & Total & 90 & 120 & 150 & 140 \\
\hline & Redefined & 17 & 24 & 9 & 0 \\
\hline Qinghal & Total & 90 & 80 & 100 & 60 \\
\hline & Redefined & 333 & 64 & 82 & 176 \\
\hline Shaanxı & Total & 1070 & 540 & 540 & 600 \\
\hline & Redefined & 2077 & 822 & 298 & 428 \\
\hline Shandong & Total & 1680 & 1540 & 1530 & 2290 \\
\hline & Redefined & -3 & 3 & 0 & -3 \\
\hline Shanghal & Total & 300 & 380 & 90 & -570 \\
\hline & Redefined & 229 & 76 & 24 & -30 \\
\hline Shanxı & Total & 660 & 570 & 540 & 540 \\
\hline & Redefined & 417 & 85 & 151 & 2 \\
\hline sichuan & Total & 1490 & 1240 & 1290 & 1430 \\
\hline Tianiin & Redefined & 0 & 51 & 0 & 15 \\
\hline Tlanjın & Total & 620 & 550 & 410 & 300 \\
\hline Ti & Redefined & 4 & 16 & 0 & 0 \\
\hline T1 & Total & 10 & 40 & 80 & 80 \\
\hline$x$; & Redefined & 46 & 48 & -2 & 73 \\
\hline ing & Total & 200 & 250 & 520 & 560 \\
\hline$Y$ & Redefined & 243 & 121 & 237 & 9 \\
\hline an & Total & 1270 & 660 & 700 & 880 \\
\hline & Redefined & 81 & 388 & 120 & 119 \\
\hline Zhejlang & Total & 580 & 580 & 540 & 720 \\
\hline
\end{tabular}

Note: Numbers are in thousands. 


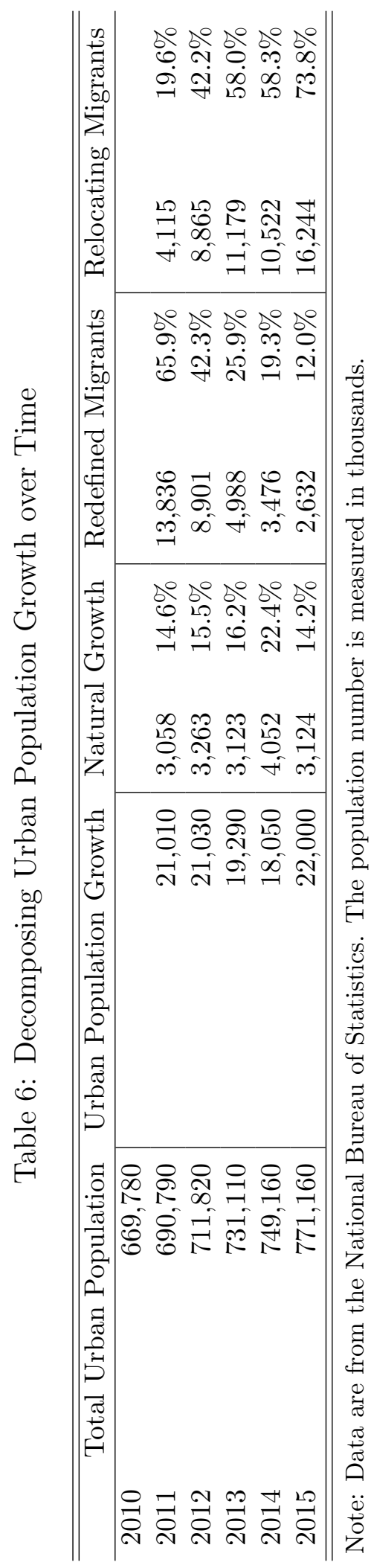


Table 7: Community Comparisons for Pooled Sample

\begin{tabular}{|c|c|c|c|c|c|c|}
\hline & $\begin{array}{c}(1) \\
\text { Urban }\end{array}$ & $\begin{array}{c}(2) \\
\text { Rural }\end{array}$ & $\begin{array}{c}(3) \\
\text { Rural to Urban }\end{array}$ & $\begin{array}{c}(4) \\
\text { Urban to Rural }\end{array}$ & $\begin{array}{c}(5) \\
(1)-(3)\end{array}$ & $\begin{array}{c}(6) \\
(2)-(3) \\
\end{array}$ \\
\hline Self-reported Rural & $\begin{array}{c}0.17 \\
(0.37)\end{array}$ & $\begin{array}{c}0.97 \\
(0.17)\end{array}$ & $\begin{array}{c}0.75 \\
(0.43)\end{array}$ & $\begin{array}{c}0.93 \\
(0.26)\end{array}$ & $\begin{array}{c}-0.59^{* * *} \\
(0.04)\end{array}$ & $\begin{array}{c}0.22^{* * *} \\
(0.02)\end{array}$ \\
\hline Number of Residents & $\begin{array}{c}7,308 \\
(6,824)\end{array}$ & $\begin{array}{c}1,956 \\
(1,818)\end{array}$ & $\begin{array}{c}2,130 \\
(1,436)\end{array}$ & $\begin{array}{c}2,020 \\
(1,595)\end{array}$ & $\begin{array}{c}5,178^{* * *} \\
(680)\end{array}$ & $\begin{array}{l}-174 \\
(185)\end{array}$ \\
\hline Registered Residents & $\begin{array}{c}5,281 \\
(4,675)\end{array}$ & $\begin{array}{c}2,082 \\
(1,687)\end{array}$ & $\begin{array}{c}2,107 \\
(1,406)\end{array}$ & $\begin{array}{c}1,887 \\
(1,439)\end{array}$ & $\begin{array}{c}3,174^{* * *} \\
(531)\end{array}$ & $\begin{array}{c}-25 \\
(196)\end{array}$ \\
\hline Ag-Hukou Ratio & $\begin{array}{c}0.26 \\
(0.40)\end{array}$ & $\begin{array}{c}0.95 \\
(0.16)\end{array}$ & $\begin{array}{c}0.94 \\
(0.19)\end{array}$ & $\begin{array}{c}0.86 \\
(0.33)\end{array}$ & $\begin{array}{c}-0.68^{* * *} \\
(0.05)\end{array}$ & $\begin{array}{c}0.02 \\
(0.02)\end{array}$ \\
\hline Registered Households & $\begin{array}{c}2,219 \\
(2,687)\end{array}$ & $\begin{array}{l}545 \\
(399)\end{array}$ & $\begin{array}{c}623 \\
(494)\end{array}$ & $\begin{array}{c}631 \\
(436)\end{array}$ & $\begin{array}{c}1,596^{* * *} \\
(269)\end{array}$ & $\begin{array}{l}-78^{*} \\
(42)\end{array}$ \\
\hline Agricultural Land & $\begin{array}{c}0.17 \\
(0.38)\end{array}$ & $\begin{array}{c}0.94 \\
(0.23)\end{array}$ & $\begin{array}{c}0.87 \\
(0.34)\end{array}$ & $\begin{array}{c}0.82 \\
(0.39)\end{array}$ & $\begin{array}{c}-0.70^{* * *} \\
(0.05)\end{array}$ & $\begin{array}{c}0.08^{* * *} \\
(0.03)\end{array}$ \\
\hline Kindergarten & $\begin{array}{c}0.70 \\
(0.46)\end{array}$ & $\begin{array}{c}0.37 \\
(0.48)\end{array}$ & $\begin{array}{c}0.49 \\
(0.50)\end{array}$ & $\begin{array}{c}0.41 \\
(0.50)\end{array}$ & $\begin{array}{c}0.21^{* * *} \\
(0.05)\end{array}$ & $\begin{array}{c}-0.12^{* *} \\
(0.06)\end{array}$ \\
\hline Number of Banks & $\begin{array}{l}1.99 \\
(2.28)\end{array}$ & $\begin{array}{c}0.37 \\
(1.07)\end{array}$ & $\begin{array}{c}0.49 \\
(0.87)\end{array}$ & $\begin{array}{c}0.59 \\
(1.20)\end{array}$ & $\begin{array}{c}1.51^{* * *} \\
(0.23)\end{array}$ & $\begin{array}{l}-0.11 \\
(0.11)\end{array}$ \\
\hline Old-Care Service & $\begin{array}{c}0.47 \\
(0.50)\end{array}$ & $\begin{array}{c}0.18 \\
(0.39)\end{array}$ & $\begin{array}{c}0.28 \\
(0.45)\end{array}$ & $\begin{array}{c}0.34 \\
(0.48)\end{array}$ & $\begin{array}{c}0.19^{* * *} \\
(0.06)\end{array}$ & $\begin{array}{c}-0.10^{* *} \\
(0.05)\end{array}$ \\
\hline Job Training Service & $\begin{array}{c}0.23 \\
(0.42)\end{array}$ & $\begin{array}{c}0.08 \\
(0.27)\end{array}$ & $\begin{array}{c}0.13 \\
(0.33)\end{array}$ & $\begin{array}{c}0.17 \\
(0.38)\end{array}$ & $\begin{array}{l}0.10^{* *} \\
(0.05)\end{array}$ & $\begin{array}{l}-0.05 \\
(0.03)\end{array}$ \\
\hline Disposable Income pc & $\begin{array}{c}19,234 \\
(32,388)\end{array}$ & $\begin{array}{c}6,646 \\
(6,068)\end{array}$ & $\begin{array}{c}8,104 \\
(6,270)\end{array}$ & $\begin{array}{c}12,888 \\
(18,886)\end{array}$ & $\begin{array}{c}11,130^{* * *} \\
(3,244)\end{array}$ & $\begin{array}{c}-1,459^{* *} \\
(629)\end{array}$ \\
\hline Poor Residents & $\begin{array}{c}0.04 \\
(0.09) \\
\end{array}$ & $\begin{array}{c}0.07 \\
(0.10) \\
\end{array}$ & $\begin{array}{c}0.08 \\
(0.13) \\
\end{array}$ & $\begin{array}{c}0.05 \\
(0.09)\end{array}$ & $\begin{array}{c}-0.04^{* * *} \\
(0.01) \\
\end{array}$ & $\begin{array}{l}-0.01 \\
(0.01)\end{array}$ \\
\hline Observations & 1875 & 1462 & 101 & 41 & & \\
\hline
\end{tabular}


Table 8: Household Comparisons for Pooled Sample

\begin{tabular}{|c|c|c|c|c|c|c|}
\hline & $\begin{array}{c}(1) \\
\text { Urban }\end{array}$ & $\begin{array}{c}(2) \\
\text { Rural }\end{array}$ & $\begin{array}{c}(3) \\
\text { Rural to Urban }\end{array}$ & $\begin{array}{c}(4) \\
\text { Urban to Rural }\end{array}$ & $\begin{array}{c}(5) \\
(1)-(3)\end{array}$ & $\begin{array}{c}(6) \\
(2)-(3)\end{array}$ \\
\hline Family Size & $\begin{array}{c}3.10 \\
(1.41)\end{array}$ & $\begin{array}{c}3.78 \\
(1.83)\end{array}$ & $\begin{array}{c}3.79 \\
(1.81)\end{array}$ & $\begin{array}{c}3.46 \\
(1.58)\end{array}$ & $\begin{array}{c}-0.69^{* * *} \\
(0.03)\end{array}$ & $\begin{array}{l}-0.01 \\
(0.04)\end{array}$ \\
\hline Number of Children & $\begin{array}{c}0.46 \\
(0.69)\end{array}$ & $\begin{array}{c}0.68 \\
(0.95)\end{array}$ & $\begin{array}{c}0.68 \\
(0.90)\end{array}$ & $\begin{array}{c}0.51 \\
(0.69)\end{array}$ & $\begin{array}{c}-0.22^{* * *} \\
(0.01)\end{array}$ & $\begin{array}{l}-0.00 \\
(0.02)\end{array}$ \\
\hline Head Schooling & $\begin{array}{l}10.46 \\
(4.02)\end{array}$ & $\begin{array}{c}6.89 \\
(3.47)\end{array}$ & $\begin{array}{c}7.15 \\
(3.60)\end{array}$ & $\begin{array}{c}7.48 \\
(3.19)\end{array}$ & $\begin{array}{l}3.32^{* * *} \\
(0.08)\end{array}$ & $\begin{array}{c}-0.26^{* * *} \\
(0.07)\end{array}$ \\
\hline Head Urban Hukou & $\begin{array}{c}0.64 \\
(0.48)\end{array}$ & $\begin{array}{c}0.03 \\
(0.17)\end{array}$ & $\begin{array}{c}0.06 \\
(0.23)\end{array}$ & $\begin{array}{c}0.10 \\
(0.30)\end{array}$ & $\begin{array}{c}0.58^{* * *} \\
(0.01)\end{array}$ & $\begin{array}{c}-0.03^{* * *} \\
(0.00)\end{array}$ \\
\hline Ag Activity & $\begin{array}{c}0.11 \\
(0.32)\end{array}$ & $\begin{array}{c}0.75 \\
(0.44)\end{array}$ & $\begin{array}{c}0.61 \\
(0.49)\end{array}$ & $\begin{array}{c}0.63 \\
(0.48)\end{array}$ & $\begin{array}{c}-0.50^{* * *} \\
(0.01)\end{array}$ & $\begin{array}{c}0.14^{* * *} \\
(0.01)\end{array}$ \\
\hline Agricultural Land & $\begin{array}{c}0.21 \\
(0.41)\end{array}$ & $\begin{array}{c}0.84 \\
(0.37)\end{array}$ & $\begin{array}{c}0.74 \\
(0.44)\end{array}$ & $\begin{array}{c}0.70 \\
(0.46)\end{array}$ & $\begin{array}{c}-0.53^{* * *} \\
(0.01)\end{array}$ & $\begin{array}{c}0.10^{* * *} \\
(0.01)\end{array}$ \\
\hline Total Income & $\begin{array}{c}90,374 \\
(441,480)\end{array}$ & $\begin{array}{c}40,786 \\
(170,892)\end{array}$ & $\begin{array}{c}48,339 \\
(99,504)\end{array}$ & $\begin{array}{c}47,618 \\
(94,565)\end{array}$ & $\begin{array}{c}42,034^{* * *} \\
(9,102)\end{array}$ & $\begin{array}{c}-7,553^{* *} \\
(3,563)\end{array}$ \\
\hline Total Consumption & $\begin{array}{c}62,821 \\
(72,487)\end{array}$ & $\begin{array}{c}35,157 \\
(43,216)\end{array}$ & $\begin{array}{c}43,161 \\
(61,805)\end{array}$ & $\begin{array}{c}41,426 \\
(50,695)\end{array}$ & $\begin{array}{c}19,660^{* * *} \\
(1,512)\end{array}$ & $\begin{array}{c}-8,004^{* * *} \\
(954)\end{array}$ \\
\hline Observations & 68287 & 32520 & 2357 & 1076 & & \\
\hline
\end{tabular}


Table 9: Housing Comparisons for Pooled Sample

\begin{tabular}{lcccc}
\hline \hline & Urban & Rural & Rural to Urban & Urban to Rural \\
\hline Willing to Buy & 0.16 & 0.08 & 0.09 & 0.09 \\
& $(0.36)$ & $(0.27)$ & $(0.28)$ & $(0.28)$ \\
Willing to Build & 0.04 & 0.11 & 0.10 & 0.08 \\
& $(0.18)$ & $(0.31)$ & $(0.30)$ & $(0.27)$ \\
Live in Own House & 0.78 & 0.95 & 0.91 & 0.90 \\
Have Own House & $(0.41)$ & $(0.23)$ & $(0.28)$ & $(0.31)$ \\
& 0.87 & 0.96 & 0.94 & 0.93 \\
Housing Usable Size & $(0.33)$ & $(0.19)$ & $(0.23)$ & $(0.25)$ \\
& 96.94 & 126.86 & 138.72 & 121.19 \\
Self-Built House & $(81.13)$ & $(94.91)$ & $(101.17)$ & $(93.09)$ \\
Collective-Owned Land & 0.30 & 0.87 & 0.86 & 0.71 \\
& $(0.46)$ & $(0.34)$ & $(0.35)$ & $(0.45)$ \\
Housing Cost & 0.15 & 0.48 & 0.58 & 0.49 \\
& $(0.36)$ & $(0.50)$ & $(0.49)$ & $(0.50)$ \\
Housing Fair Value & 189,741 & 63,377 & 82,744 & 65,612 \\
& $(380,474)$ & $(120,496)$ & $(153,465)$ & $(113,515)$ \\
\hline Observations & 778,791 & 146,128 & 290,012 & 175,447 \\
\hline \hline
\end{tabular}

Means and standard errors (in parentheses) are presented. 
Table 10: Balanced Test

\begin{tabular}{|c|c|c|c|c|}
\hline & (1) & (2) & (3) & $\overline{(4)}$ \\
\hline Ln(Area) & $\begin{array}{l}-0.001 \\
(0.001)\end{array}$ & $\begin{array}{c}-0.002 \\
(0.002)\end{array}$ & $\begin{array}{c}-0.002 \\
(0.002)\end{array}$ & $\begin{array}{c}-0.002 \\
(0.004)\end{array}$ \\
\hline Number of Roads & $\begin{array}{c}-0.004 \\
(0.006)\end{array}$ & $\begin{array}{l}-0.003 \\
(0.008)\end{array}$ & $\begin{array}{l}-0.004 \\
(0.008)\end{array}$ & $\begin{array}{l}-0.006 \\
(0.014)\end{array}$ \\
\hline Agricultural Land & $\begin{array}{l}0.012^{* *} \\
(0.005)\end{array}$ & $\begin{array}{l}-0.001 \\
(0.007)\end{array}$ & $\begin{array}{c}0.001 \\
(0.007)\end{array}$ & $\begin{array}{c}0.000 \\
(0.005)\end{array}$ \\
\hline Ln(Residents) & $\begin{array}{l}0.016^{* *} \\
(0.007)\end{array}$ & $\begin{array}{c}0.011 \\
(0.010)\end{array}$ & $\begin{array}{c}0.014 \\
(0.012)\end{array}$ & $\begin{array}{c}0.020 \\
(0.017)\end{array}$ \\
\hline Ln(Households) & $\begin{array}{c}-0.019^{* *} \\
(0.010)\end{array}$ & $\begin{array}{c}-0.004 \\
(0.014)\end{array}$ & $\begin{array}{c}-0.008 \\
(0.016)\end{array}$ & $\begin{array}{c}-0.010 \\
(0.020)\end{array}$ \\
\hline Ln(Migrants) & $\begin{array}{l}-0.002 \\
(0.002)\end{array}$ & $\begin{array}{l}-0.001 \\
(0.003)\end{array}$ & $\begin{array}{c}-0.001 \\
(0.003)\end{array}$ & $\begin{array}{c}0.001 \\
(0.004)\end{array}$ \\
\hline Poor Residents & $\begin{array}{c}0.008 \\
(0.039)\end{array}$ & $\begin{array}{c}-0.006 \\
(0.057)\end{array}$ & $\begin{array}{c}0.010 \\
(0.057)\end{array}$ & $\begin{array}{c}0.040 \\
(0.076)\end{array}$ \\
\hline Ln(Household Income) & $\begin{array}{c}0.005 \\
(0.006)\end{array}$ & $\begin{array}{c}-0.004 \\
(0.005)\end{array}$ & $\begin{array}{l}-0.005 \\
(0.005)\end{array}$ & $\begin{array}{c}-0.009 \\
(0.009)\end{array}$ \\
\hline County FE & No & Yes & Yes & Yes \\
\hline Year FE & No & No & Yes & Yes \\
\hline County*Year FE & No & No & No & Yes \\
\hline$R^{2}$ & 0.008 & 0.519 & 0.520 & 0.612 \\
\hline Observations & 813 & 813 & 813 & 813 \\
\hline
\end{tabular}

Robust standard errors are clustered at the county level.

${ }^{*} p<0.1,{ }^{* *} p<0.05,{ }^{* * *} p<0.01$ 
Table 11: Effects of Village Reclassification: Homeownership

\begin{tabular}{|c|c|c|c|c|c|}
\hline & (1) & $(2)$ & (3) & (4) & $(5)$ \\
\hline Reclassified & $\begin{array}{l}-0.015 \\
(0.060)\end{array}$ & $\begin{array}{l}-0.015 \\
(0.060)\end{array}$ & $\begin{array}{l}-0.034 \\
(0.063)\end{array}$ & $\begin{array}{l}-0.017 \\
(0.057)\end{array}$ & $\begin{array}{l}-0.015 \\
(0.059)\end{array}$ \\
\hline Family Size & & $\begin{array}{c}0.018^{* * *} \\
(0.001)\end{array}$ & & $\begin{array}{c}0.018^{* * *} \\
(0.001)\end{array}$ & $\begin{array}{c}0.017^{* * *} \\
(0.003)\end{array}$ \\
\hline Female Head & & $\begin{array}{c}0.004 \\
(0.005)\end{array}$ & & $\begin{array}{c}0.003 \\
(0.005)\end{array}$ & $\begin{array}{c}0.006 \\
(0.014)\end{array}$ \\
\hline Head Age & & $\begin{array}{c}-0.000^{* * *} \\
(0.000)\end{array}$ & & $\begin{array}{c}-0.000^{* * *} \\
(0.000)\end{array}$ & $\begin{array}{l}-0.000 \\
(0.000)\end{array}$ \\
\hline Head Schooling & & $\begin{array}{c}0.001 \\
(0.000)\end{array}$ & & $\begin{array}{c}0.001 \\
(0.000)\end{array}$ & $\begin{array}{c}0.002 \\
(0.001)\end{array}$ \\
\hline Number of Children & & $\begin{array}{c}-0.016^{* * *} \\
(0.002)\end{array}$ & & $\begin{array}{c}-0.015^{* * *} \\
(0.002)\end{array}$ & $\begin{array}{c}-0.018^{* * *} \\
(0.004)\end{array}$ \\
\hline Number of Elderly & & $\begin{array}{c}-0.016^{* * *} \\
(0.002)\end{array}$ & & $\begin{array}{c}-0.016^{* * *} \\
(0.002)\end{array}$ & $\begin{array}{c}-0.019^{* * *} \\
(0.006)\end{array}$ \\
\hline Married & & $\begin{array}{c}0.036^{* * *} \\
(0.006)\end{array}$ & & $\begin{array}{c}0.035^{* * *} \\
(0.006)\end{array}$ & $\begin{array}{c}0.038^{* * *} \\
(0.010)\end{array}$ \\
\hline Agricutural Land & & $\begin{array}{c}0.039^{* * *} \\
(0.004)\end{array}$ & & $\begin{array}{c}0.039^{* * *} \\
(0.004)\end{array}$ & $\begin{array}{c}0.045^{* * *} \\
(0.008)\end{array}$ \\
\hline Community FE & Yes & Yes & No & Yes & Yes \\
\hline Year FE & Yes & Yes & Yes & Yes & Yes \\
\hline Household FE & No & No & Yes & No & No \\
\hline Province*Year FE & No & No & No & Yes & No \\
\hline Household Characteristics*Year Effects & No & No & No & No & Yes \\
\hline$R^{2}$ & 0.058 & 0.093 & 0.003 & 0.097 & 0.094 \\
\hline
\end{tabular}

Robust standard errors are clustered at the community level.

R-squred reported in the specification with household fixed effects is the within R-suqred.

${ }^{*} p<0.1,{ }^{* *} p<0.05,{ }^{* * *} p<0.01$ 
Table 12: Effects of Village Reclassification: Multiple Homeownership

\begin{tabular}{|c|c|c|c|c|c|}
\hline & (1) & (2) & (3) & (4) & $(5)$ \\
\hline Reclassified & $\begin{array}{l}-0.042 \\
(0.086)\end{array}$ & $\begin{array}{l}-0.043 \\
(0.086)\end{array}$ & $\begin{array}{l}-0.040 \\
(0.097)\end{array}$ & $\begin{array}{l}-0.038 \\
(0.086)\end{array}$ & $\begin{array}{l}-0.043 \\
(0.085)\end{array}$ \\
\hline Family Size & & $\begin{array}{c}0.061^{* * *} \\
(0.003)\end{array}$ & & $\begin{array}{c}0.061^{* * *} \\
(0.003)\end{array}$ & $\begin{array}{c}0.050^{* * *} \\
(0.005)\end{array}$ \\
\hline Female Head & & $\begin{array}{l}0.017^{*} \\
(0.010)\end{array}$ & & $\begin{array}{l}0.017^{*} \\
(0.010)\end{array}$ & $\begin{array}{c}0.023 \\
(0.019)\end{array}$ \\
\hline Head Age & & $\begin{array}{l}0.001^{* *} \\
(0.000)\end{array}$ & & $\begin{array}{l}0.001^{* *} \\
(0.000)\end{array}$ & $\begin{array}{l}0.002^{* *} \\
(0.001)\end{array}$ \\
\hline Head Schooling & & $\begin{array}{c}0.008^{* * *} \\
(0.001)\end{array}$ & & $\begin{array}{c}0.008^{* * *} \\
(0.001)\end{array}$ & $\begin{array}{c}0.010^{* * *} \\
(0.002)\end{array}$ \\
\hline Number of Children & & $\begin{array}{c}-0.039^{* * *} \\
(0.005)\end{array}$ & & $\begin{array}{c}-0.039^{* * *} \\
(0.005)\end{array}$ & $\begin{array}{c}-0.025^{* *} \\
(0.010)\end{array}$ \\
\hline Number of Elderly & & $\begin{array}{c}-0.039^{* * *} \\
(0.005)\end{array}$ & & $\begin{array}{c}-0.039^{* * *} \\
(0.005)\end{array}$ & $\begin{array}{c}-0.037^{* * *} \\
(0.012)\end{array}$ \\
\hline Married & & $\begin{array}{c}0.034^{* * *} \\
(0.010)\end{array}$ & & $\begin{array}{c}0.034^{* * *} \\
(0.010)\end{array}$ & $\begin{array}{l}0.038^{* *} \\
(0.019)\end{array}$ \\
\hline Agricutural Land & & $\begin{array}{c}0.050^{* * *} \\
(0.008)\end{array}$ & & $\begin{array}{c}0.049^{* * *} \\
(0.008)\end{array}$ & $\begin{array}{c}0.057^{* * *} \\
(0.014)\end{array}$ \\
\hline Community FE & Yes & Yes & No & Yes & Yes \\
\hline Year FE & Yes & Yes & Yes & Yes & Yes \\
\hline Household FE & No & No & Yes & No & No \\
\hline Province*Year FE & No & No & No & Yes & No \\
\hline Household Characteristics*Year Effects & No & No & No & No & Yes \\
\hline$R^{2}$ & 0.064 & 0.109 & 0.001 & 0.113 & 0.111 \\
\hline Observations & 32706 & 32622 & 32706 & 32622 & 32622 \\
\hline
\end{tabular}

Robust standard errors are clustered at the community level.

$\mathrm{R}$-squred reported in the specification with household fixed effects is the within $\mathrm{R}$-suqred.

${ }^{*} p<0.1,{ }^{* *} p<0.05,{ }^{* * *} p<0.01$ 
Table 13: Effects of Village Reclassification: Add Pre-Treatment Indicator

\begin{tabular}{|c|c|c|c|c|}
\hline & \multicolumn{2}{|c|}{ Homeownership } & \multicolumn{2}{|c|}{ Multiple Homeownership } \\
\hline & $(1)$ & $(2)$ & $(3)$ & $(4)$ \\
\hline \multirow[t]{2}{*}{ Reclassified } & -0.010 & -0.006 & 0.029 & 0.039 \\
\hline & $(0.037)$ & $(0.036)$ & $(0.053)$ & $(0.053)$ \\
\hline \multirow[t]{2}{*}{ 1-2 Years Before } & 0.007 & 0.012 & 0.097 & 0.112 \\
\hline & $(0.044)$ & $(0.043)$ & $(0.080)$ & $(0.079)$ \\
\hline Community FE & Yes & Yes & Yes & Yes \\
\hline Year FE & Yes & Yes & Yes & Yes \\
\hline Household Characteristics & No & Yes & No & Yes \\
\hline$R^{2}$ & 0.058 & 0.093 & 0.064 & 0.109 \\
\hline Observations & 34876 & 34789 & 32706 & 32622 \\
\hline
\end{tabular}

Robust standard errors are clustered at the community level.

${ }^{*} p<0.1,{ }^{* *} p<0.05,{ }^{* * *} p<0.01$ 
Table 14: Effects of Village Reclassification: Drop Provinces w/o Reclassified Villages

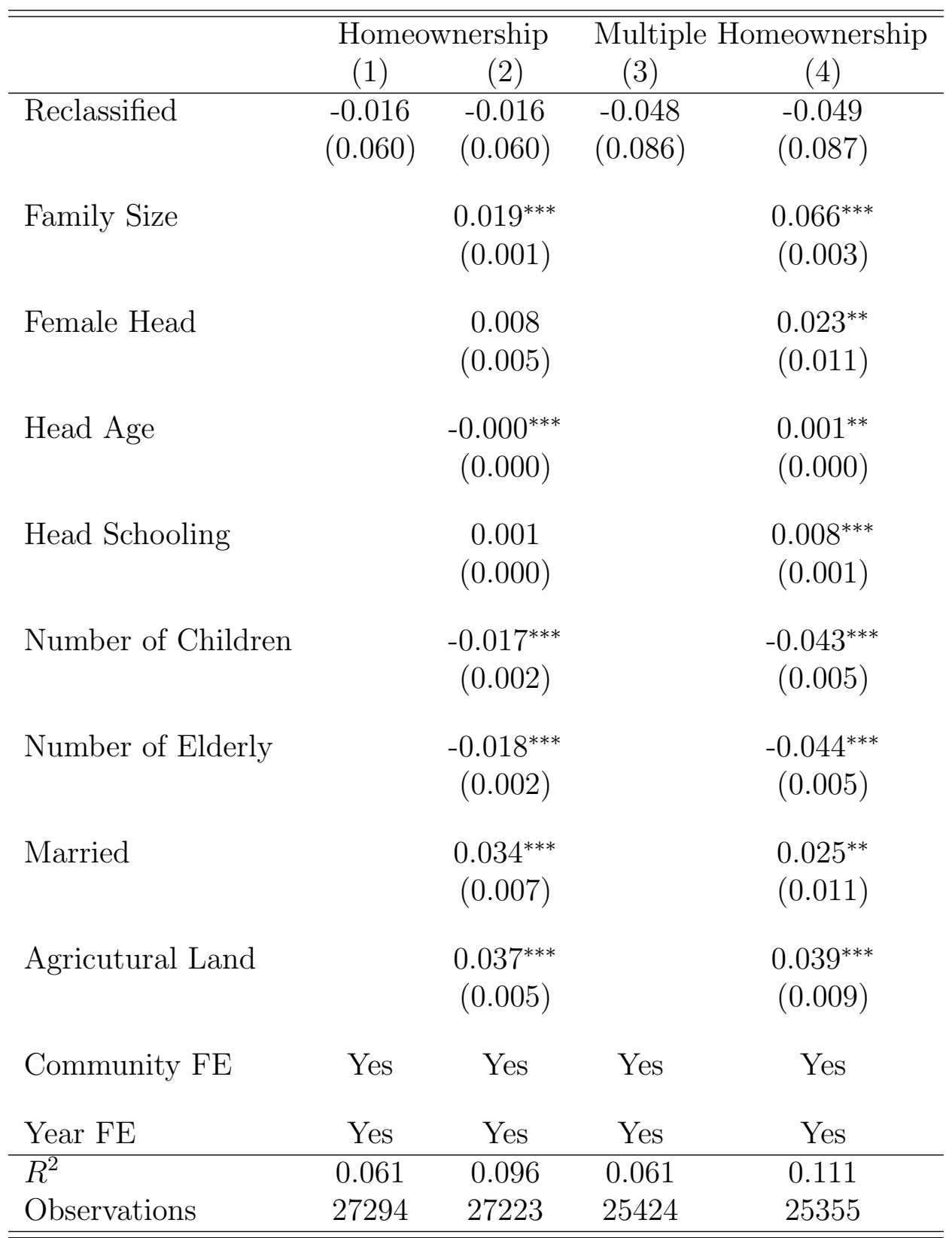

Robust standard errors are clustered at the community level.

${ }^{*} p<0.1,{ }^{* *} p<0.05,{ }^{* * *} p<0.01$ 
Table 15: Effects of Village Reclassification: Attrition from Survey

\begin{tabular}{|c|c|c|c|}
\hline & (1) & $(2)$ & (3) \\
\hline Reclassified & $\begin{array}{l}-0.049 \\
(0.232)\end{array}$ & $\begin{array}{l}-0.051 \\
(0.234)\end{array}$ & $\begin{array}{c}0.008 \\
(0.007)\end{array}$ \\
\hline Family Size & & $\begin{array}{c}-0.005^{* * *} \\
(0.002)\end{array}$ & \\
\hline Female Head & & $\begin{array}{c}0.010 \\
(0.007)\end{array}$ & \\
\hline Head Age & & $\begin{array}{c}-0.001^{* * *} \\
(0.000)\end{array}$ & \\
\hline Head Schooling & & $\begin{array}{l}-0.001^{*} \\
(0.001)\end{array}$ & \\
\hline Number of Children & & $\begin{array}{c}0.000 \\
(0.003)\end{array}$ & \\
\hline Number of Elderly & & $\begin{array}{c}0.002 \\
(0.003)\end{array}$ & \\
\hline Married & & $\begin{array}{c}-0.049^{* * *} \\
(0.007)\end{array}$ & \\
\hline Agricutural Land & & $\begin{array}{c}-0.016^{* * *} \\
(0.006)\end{array}$ & \\
\hline Community FE & Yes & Yes & No \\
\hline Year FE & Yes & Yes & Yes \\
\hline Household FE & No & No & Yes \\
\hline$R^{2}$ & 0.359 & 0.362 & 0.080 \\
\hline Observations & 21393 & 21364 & 21393 \\
\hline
\end{tabular}

Robust standard errors are clustered at the community level.

${ }^{*} p<0.1,{ }^{* *} p<0.05,{ }^{* * *} p<0.01$ 
Table 16: Effects of Village Reclassification: Alternative Housing Measures

\begin{tabular}{|c|c|c|c|c|}
\hline & $\begin{array}{c}(1) \\
\text { No.Room }\end{array}$ & $\begin{array}{c}(2) \\
\operatorname{Ln}(\text { Size })\end{array}$ & $\begin{array}{c}(3) \\
\text { Self-Built }\end{array}$ & $\begin{array}{c}(4) \\
\text { Willing to Buy }\end{array}$ \\
\hline Reclassified & $\begin{array}{c}0.400 \\
(0.556)\end{array}$ & $\begin{array}{l}-0.030 \\
(0.030)\end{array}$ & $\begin{array}{l}-0.000 \\
(0.037)\end{array}$ & $\begin{array}{l}-0.054 \\
(0.033)\end{array}$ \\
\hline Family Size & $\begin{array}{l}0.466^{*} \\
(0.242)\end{array}$ & $\begin{array}{c}0.055^{* * *} \\
(0.004)\end{array}$ & $\begin{array}{c}0.009^{* * *} \\
(0.002)\end{array}$ & $\begin{array}{c}0.016^{* * *} \\
(0.002)\end{array}$ \\
\hline Female Head & $\begin{array}{l}-0.303 \\
(0.377)\end{array}$ & $\begin{array}{c}0.022 \\
(0.015)\end{array}$ & $\begin{array}{l}-0.004 \\
(0.008)\end{array}$ & $\begin{array}{c}0.006 \\
(0.007)\end{array}$ \\
\hline Head Age & $\begin{array}{c}0.093 \\
(0.093)\end{array}$ & $\begin{array}{c}-0.001^{* *} \\
(0.001)\end{array}$ & $\begin{array}{c}0.002^{* * *} \\
(0.000)\end{array}$ & $\begin{array}{c}-0.002^{* * *} \\
(0.000)\end{array}$ \\
\hline Head Schooling & $\begin{array}{l}-0.122 \\
(0.167)\end{array}$ & $\begin{array}{c}0.009^{* * *} \\
(0.002)\end{array}$ & $\begin{array}{c}0.001 \\
(0.001)\end{array}$ & $\begin{array}{c}0.004^{* * *} \\
(0.001)\end{array}$ \\
\hline Number of Children & $\begin{array}{c}0.188 \\
(0.310)\end{array}$ & $\begin{array}{c}-0.032^{* * *} \\
(0.007)\end{array}$ & $\begin{array}{c}-0.012^{* * *} \\
(0.004)\end{array}$ & $\begin{array}{c}-0.012^{* * *} \\
(0.004)\end{array}$ \\
\hline Number of Elderly & $\begin{array}{l}-0.198 \\
(0.128)\end{array}$ & $\begin{array}{c}-0.038^{* * *} \\
(0.008)\end{array}$ & $\begin{array}{c}0.000 \\
(0.003)\end{array}$ & $\begin{array}{c}-0.012^{* * *} \\
(0.003)\end{array}$ \\
\hline Married & $\begin{array}{c}2.748 \\
(2.513)\end{array}$ & $\begin{array}{c}0.138^{* * *} \\
(0.017)\end{array}$ & $\begin{array}{l}0.017^{* *} \\
(0.008)\end{array}$ & $\begin{array}{l}-0.002 \\
(0.006)\end{array}$ \\
\hline Agricutural Land & $\begin{array}{c}0.057 \\
(0.090)\end{array}$ & $\begin{array}{c}0.037^{* * *} \\
(0.011)\end{array}$ & $\begin{array}{c}0.026^{* * *} \\
(0.006)\end{array}$ & $\begin{array}{c}0.005 \\
(0.007)\end{array}$ \\
\hline Community FE & Yes & Yes & Yes & Yes \\
\hline Year FE & Yes & Yes & Yes & Yes \\
\hline$R^{2}$ & 0.027 & 0.225 & 0.154 & 0.089 \\
\hline Observations & 31823 & 30632 & 31875 & 17244 \\
\hline
\end{tabular}

Robust standard errors are clustered at the community level.

${ }^{*} p<0.1,{ }^{* *} p<0.05,{ }^{* * *} p<0.01$ 
Table 17: Effects of Village Reclassification: Welfare

\begin{tabular}{lccc}
\hline \hline & $(1)$ & $(2)$ & $(3)$ \\
& Ln(Income pc) & $\operatorname{Ln}($ Consumption pc) & Ln(Non-Food Consumption pc) \\
\hline Reclassified & 0.109 & 0.009 & -0.046 \\
Female Head & $(0.103)$ & $(0.075)$ & $(0.102)$ \\
& -0.003 & $0.041^{* *}$ & 0.032 \\
Head Age & $(0.026)$ & $(0.016)$ & $(0.020)$ \\
& $-0.006^{* * *}$ & $-0.007^{* * *}$ & $-0.009^{* * *}$ \\
Head Schooling & $(0.001)$ & $(0.001)$ & $(0.001)$ \\
& $0.047^{* * *}$ & $0.024^{* * *}$ & $0.027^{* * *}$ \\
Number of Children & $(0.002)$ & $(0.002)$ & $(0.002)$ \\
& $-0.134^{* * *}$ & $-0.140^{* * *}$ & $-0.137^{* * *}$ \\
Number of Elderly & $(0.009)$ & $(0.006)$ & $(0.006)$ \\
& $-0.164^{* * *}$ & $-0.097^{* * *}$ & $-0.106^{* * *}$ \\
Married & $(0.011)$ & $(0.007)$ & $(0.008)$ \\
& $0.065^{* *}$ & -0.007 & $0.099^{* * *}$ \\
Agricutural Land & $(0.026)$ & $(0.017)$ & $(0.020)$ \\
Community FE & $0.143^{* * *}$ & -0.004 & $0.057^{* * *}$ \\
Year FE & $(0.024)$ & $(0.013)$ & $(0.017)$ \\
\hline$R^{2}$ & Yes & Yes & Yes \\
Observations & Yes & Yes & Yes \\
\hline \hline
\end{tabular}

Robust standard errors are clustered at the community level.

${ }^{*} p<0.1,{ }^{* *} p<0.05,{ }^{* * *} p<0.01$ 
Table 18: Household Comparisons for CHFS 2017

\begin{tabular}{|c|c|c|c|c|c|c|c|c|c|}
\hline & Rural & 2010 & 2011 & 2012 & 2013 & 2014 & 2015 & 2016 & 2017 \\
\hline Family Size & $\begin{array}{c}3.55 \\
(1.77)\end{array}$ & $\begin{array}{c}3.92 \\
(1.92)\end{array}$ & $\begin{array}{c}3.53 \\
(1.86)\end{array}$ & $\begin{array}{c}3.84 \\
(1.77)\end{array}$ & $\begin{array}{c}3.80 \\
(1.76)\end{array}$ & $\begin{array}{c}4.11 \\
(1.88)\end{array}$ & $\begin{array}{c}3.29 \\
(1.51)\end{array}$ & $\begin{array}{c}3.23 \\
(1.70)\end{array}$ & $\begin{array}{c}2.90 \\
(1.37)\end{array}$ \\
\hline Number of Children & $\begin{array}{c}0.62 \\
(0.92)\end{array}$ & $\begin{array}{c}0.85 \\
(0.97)\end{array}$ & $\begin{array}{c}0.64 \\
(0.94)\end{array}$ & $\begin{array}{c}0.76 \\
(0.97)\end{array}$ & $\begin{array}{c}0.78 \\
(0.98)\end{array}$ & $\begin{array}{c}0.89 \\
(1.16)\end{array}$ & $\begin{array}{c}0.41 \\
(0.64)\end{array}$ & $\begin{array}{c}0.48 \\
(0.76)\end{array}$ & $\begin{array}{c}0.30 \\
(0.69)\end{array}$ \\
\hline Head Schooling & $\begin{array}{c}6.96 \\
(3.46)\end{array}$ & $\begin{array}{c}7.50 \\
(3.46)\end{array}$ & $\begin{array}{c}7.09 \\
(3.66)\end{array}$ & $\begin{array}{c}7.36 \\
(3.25)\end{array}$ & $\begin{array}{c}7.62 \\
(3.40)\end{array}$ & $\begin{array}{c}4.88 \\
(4.33)\end{array}$ & $\begin{array}{c}7.78 \\
(3.68)\end{array}$ & $\begin{array}{c}7.40 \\
(3.55)\end{array}$ & $\begin{array}{c}6.75 \\
(4.11)\end{array}$ \\
\hline Head Urban Hukou & $\begin{array}{c}0.03 \\
(0.18)\end{array}$ & $\begin{array}{c}0.08 \\
(0.27)\end{array}$ & $\begin{array}{c}0.04 \\
(0.19)\end{array}$ & $\begin{array}{c}0.04 \\
(0.21)\end{array}$ & $\begin{array}{c}0.03 \\
(0.17)\end{array}$ & $\begin{array}{c}0.05 \\
(0.21)\end{array}$ & $\begin{array}{c}0.00 \\
(0.00)\end{array}$ & $\begin{array}{c}0.03 \\
(0.18)\end{array}$ & $\begin{array}{c}0.31 \\
(0.46)\end{array}$ \\
\hline Ag Activity & $\begin{array}{c}0.75 \\
(0.43)\end{array}$ & $\begin{array}{c}0.58 \\
(0.49)\end{array}$ & $\begin{array}{c}0.70 \\
(0.46)\end{array}$ & $\begin{array}{c}0.55 \\
(0.50)\end{array}$ & $\begin{array}{c}0.65 \\
(0.48)\end{array}$ & $\begin{array}{c}0.13 \\
(0.33)\end{array}$ & $\begin{array}{c}0.44 \\
(0.50)\end{array}$ & $\begin{array}{c}0.39 \\
(0.49)\end{array}$ & $\begin{array}{c}0.54 \\
(0.50)\end{array}$ \\
\hline Agricultural Land & $\begin{array}{c}0.80 \\
(0.40)\end{array}$ & $\begin{array}{c}0.59 \\
(0.49)\end{array}$ & $\begin{array}{c}0.79 \\
(0.41)\end{array}$ & $\begin{array}{c}0.64 \\
(0.48)\end{array}$ & $\begin{array}{c}0.69 \\
(0.47)\end{array}$ & $\begin{array}{c}0.41 \\
(0.50)\end{array}$ & $\begin{array}{c}0.65 \\
(0.48)\end{array}$ & $\begin{array}{c}0.58 \\
(0.50)\end{array}$ & $\begin{array}{c}0.56 \\
(0.50)\end{array}$ \\
\hline Total Income & $\begin{array}{c}45,227 \\
(73,563)\end{array}$ & $\begin{array}{c}49,470 \\
(59,060)\end{array}$ & $\begin{array}{c}41,369 \\
(56,717)\end{array}$ & $\begin{array}{c}63,154 \\
(93,987)\end{array}$ & $\begin{array}{c}45,784 \\
(90,012)\end{array}$ & $\begin{array}{c}35,411 \\
(33,782)\end{array}$ & $\begin{array}{c}78,265 \\
(93,936)\end{array}$ & $\begin{array}{c}45,561 \\
(61,929)\end{array}$ & $\begin{array}{c}60,680 \\
(64,604)\end{array}$ \\
\hline Total Consumption & $\begin{array}{c}37,091 \\
(38,199)\end{array}$ & $\begin{array}{c}44,165 \\
(42,957)\end{array}$ & $\begin{array}{c}32,322 \\
(31,325)\end{array}$ & $\begin{array}{c}58,397 \\
(50,308)\end{array}$ & $\begin{array}{c}61,333 \\
(71,967)\end{array}$ & $\begin{array}{c}58,984 \\
(37,473)\end{array}$ & $\begin{array}{c}54,761 \\
(51,326)\end{array}$ & $\begin{array}{c}37,124 \\
(41,200)\end{array}$ & $\begin{array}{c}38,896 \\
(30,679)\end{array}$ \\
\hline Observations & 11425 & 142 & 325 & 135 & 65 & 64 & 85 & 62 & 91 \\
\hline
\end{tabular}


Table 19: Urban Population and Residential Land

\begin{tabular}{lcccc}
\hline \hline & $(1)$ & $(2)$ & $(3)$ & $(4)$ \\
\hline Ln(Urban Population) & $0.498^{* * *}$ & $0.603^{* * *}$ & $0.629^{* * *}$ & $0.650^{* *}$ \\
& $(0.158)$ & $(0.178)$ & $(0.165)$ & $(0.279)$ \\
Ln(City Size) & & $0.129^{* * *}$ & $0.128^{* * *}$ & 0.009 \\
& & $(0.045)$ & $(0.042)$ & $(0.038)$ \\
Ln(Road Size pc) & & 0.280 & 0.284 & 0.438 \\
& & $(0.234)$ & $(0.221)$ & $(0.285)$ \\
Ln(Greenland Size pc) & & -0.045 & -0.051 & -0.028 \\
& & $(0.065)$ & $(0.070)$ & $(0.040)$ \\
Ln(GDP pc) & & -0.128 & -0.136 & -0.158 \\
& & $(0.100)$ & $(0.102)$ & $(0.165)$ \\
Ln(Fiscal Income pc) & & -0.012 & -0.007 & -0.005 \\
& & $(0.012)$ & $(0.011)$ & $(0.006)$ \\
Prefecture FE & Yes & Yes & Yes & Yes \\
Year FE & Yes & Yes & Yes & Yes \\
Region by Year FE & No & No & Yes & No \\
Prefecture Linear Trend & No & No & No & Yes \\
\hline$R^{2}$ & 0.095 & 0.129 & 0.145 & 0.631 \\
Observations & 1581 & 1465 & 1465 & 1465 \\
\hline \hline
\end{tabular}

Standard errors are clustered at the prefecture level.

Reported R-squres are the within R-squares from prefecture fixed effects regressions

${ }^{*} p<0.1,{ }^{* *} p<0.05,{ }^{* * *} p<0.01$ 
Table 20: Prefecture Population and Residential Land

\begin{tabular}{lcccc}
\hline \hline & $(1)$ & $(2)$ & $(3)$ & $(4)$ \\
\hline Ln(Total Population) & $0.676^{* * *}$ & 0.528 & & \\
& $(0.241)$ & $(0.379)$ & & \\
Ln(Hukou Population) & & & -0.474 & -0.118 \\
& & & $(1.213)$ & $(0.737)$ \\
Ln(City Size) & $0.127^{* * *}$ & 0.010 & $0.137^{* *}$ & 0.015 \\
& $(0.046)$ & $(0.039)$ & $(0.053)$ & $(0.037)$ \\
Ln(Road Size pc) & 0.292 & 0.428 & 0.254 & 0.388 \\
& $(0.239)$ & $(0.289)$ & $(0.213)$ & $(0.262)$ \\
Ln(Greenland Size pc) & -0.030 & -0.030 & -0.044 & -0.042 \\
& $(0.063)$ & $(0.040)$ & $(0.069)$ & $(0.043)$ \\
Ln(GDP pc) & -0.074 & -0.152 & -0.103 & -0.173 \\
& $(0.101)$ & $(0.167)$ & $(0.100)$ & $(0.165)$ \\
Ln(Fiscal Income pc) & -0.005 & -0.005 & -0.009 & -0.008 \\
& $(0.011)$ & $(0.006)$ & $(0.012)$ & $(0.006)$ \\
Prefecture FE & Yes & Yes & Yes & Yes \\
Year FE & Yes & Yes & Yes & Yes \\
Prefecture Linear Trend & No & Yes & No & Yes \\
\hline$R^{2}$ & 0.125 & 0.627 & 0.121 & 0.625 \\
Observations & 1465 & 1465 & 1465 & 1465 \\
\hline \hline Star & & & \\
\hline
\end{tabular}

Standard errors are clustered at the prefecture level.

Reported R-squres are the within R-squares from prefecture fixed effects regressions

${ }^{*} p<0.1,{ }^{* *} p<0.05,{ }^{* * *} p<0.01$ 
Table 21: Urban Population and Residential Land: by Prefecture Tiers

\begin{tabular}{lccc}
\hline \hline & Tier 2-3 & Tier 2 & Tier 3 \\
\hline Ln(Urban Population) & $0.538^{* * *}$ & 0.119 & $0.583^{* * *}$ \\
& $(0.167)$ & $(0.420)$ & $(0.175)$ \\
Ln(City Size) & $0.121^{* * *}$ & 0.038 & $0.125^{* *}$ \\
& $(0.045)$ & $(0.071)$ & $(0.049)$ \\
Ln(Road Size pc) & 0.267 & 0.065 & 0.296 \\
& $(0.235)$ & $(0.083)$ & $(0.264)$ \\
$\operatorname{Ln}($ Greenland Size pc) & -0.048 & -0.048 & -0.050 \\
& $(0.065)$ & $(0.076)$ & $(0.072)$ \\
$\operatorname{Ln}($ GDP pc) & -0.060 & -0.036 & -0.066 \\
& $(0.060)$ & $(0.070)$ & $(0.081)$ \\
Ln(Fiscal Income pc) & -0.016 & 0.219 & -0.017 \\
& $(0.012)$ & $(0.139)$ & $(0.013)$ \\
Prefecture FE & & & \\
& Yes & Yes & Yes \\
Year FE & Yes & Yes & Yes \\
\hline$R^{2}$ & 0.137 & 0.453 & 0.127 \\
Observations & 1447 & 227 & 1220 \\
\hline \hline
\end{tabular}

Standard errors are clustered at the prefecture level.

Reported R-squres are the within R-squares from prefecture fixed effects regressions

${ }^{*} p<0.1,{ }^{* *} p<0.05,{ }^{* * *} p<0.01$ 
Table 22: Urban Population Growth and Annual Residential Land Supply

\begin{tabular}{lcccc}
\hline \hline & $(1)$ & $(2)$ & $(3)$ & $(4)$ \\
\hline Ln(Total UPG) & $0.610^{* * *}$ & & & \\
& $(0.100)$ & & & \\
Ln(Net UPG) & & $0.310^{* * *}$ & & $0.307^{* * *}$ \\
& & $(0.049)$ & & $(0.043)$ \\
Ln(Redefined) & & & $0.247^{* * *}$ & $0.292^{* * *}$ \\
& & & $(0.049)$ & $(0.059)$ \\
Ln(Residential Size pc) & 0.149 & 0.005 & -0.003 & 0.041 \\
& $(0.093)$ & $(0.156)$ & $(0.118)$ & $(0.117)$ \\
Ln(GDP pc) & $0.512^{* * *}$ & $0.457^{* *}$ & $0.533^{* *}$ & $0.550^{* *}$ \\
& $(0.148)$ & $(0.195)$ & $(0.229)$ & $(0.240)$ \\
Ln(Fiscal Income pc) & -0.194 & -0.155 & -0.093 & -0.221 \\
& $(0.147)$ & $(0.155)$ & $(0.168)$ & $(0.207)$ \\
Ln(Road Size pc) & 0.142 & $0.236^{*}$ & 0.228 & 0.292 \\
& $(0.137)$ & $(0.134)$ & $(0.169)$ & $(0.183)$ \\
Ln(Green Size pc) & $-0.176^{* *}$ & $-0.224^{*}$ & $-0.234^{*}$ & $-0.215^{*}$ \\
& $(0.080)$ & $(0.123)$ & $(0.121)$ & $(0.119)$ \\
Province FE & Yes & Yes & Yes & Yes \\
\hline$R^{2}$ & 0.700 & 0.607 & 0.583 & 0.689 \\
Observations & 246 & 224 & 235 & 191 \\
\hline \hline
\end{tabular}

Standard errors are clustered at the province level.

${ }^{*} p<0.1,{ }^{* *} p<0.05,{ }^{* * *} p<0.01$ 
Table 23: Urban Population Growth and Annual Residential Land Supply

\begin{tabular}{lccc}
\hline \hline & Tier 2-3 & Tier 2 & Tier 3 \\
\hline Ln(Net UPG) & $0.315^{* * *}$ & 0.770 & $0.215^{* * *}$ \\
& $(0.049)$ & $(1.830)$ & $(0.063)$ \\
Ln(Redefined) & $0.290^{* * *}$ & -0.073 & $0.269^{* * *}$ \\
& $(0.059)$ & $(1.112)$ & $(0.046)$ \\
Ln(Residential Size pc) & 0.031 & $3.889^{* * *}$ & -0.058 \\
& $(0.117)$ & $(0.904)$ & $(0.122)$ \\
Ln(GDP pc) & $0.534^{* *}$ & -0.147 & $0.344^{*}$ \\
& $(0.238)$ & $(3.550)$ & $(0.182)$ \\
Ln(Fiscal Income pc) & -0.192 & 0.181 & -0.146 \\
& $(0.210)$ & $(3.126)$ & $(0.188)$ \\
Ln(Road Size pc) & 0.294 & -0.899 & 0.316 \\
& $(0.183)$ & $(1.063)$ & $(0.191)$ \\
Ln(Green Size pc) & -0.210 & $-1.719^{*}$ & -0.216 \\
& $(0.129)$ & $(0.911)$ & $(0.143)$ \\
Province FE & & & \\
\hline$R^{2}$ & Yes & Yes & Yes \\
Observations & 0.692 & 0.957 & 0.653 \\
\hline \hline
\end{tabular}

Standard errors are clustered at the province level.

${ }^{*} p<0.1,{ }^{* *} p<0.05,{ }^{* * *} p<0.01$ 
Table 24: Urban Population Growth and City Nighttime Light

\begin{tabular}{|c|c|c|c|c|}
\hline & (1) & $\overline{(2)}$ & $\overline{(3)}$ & $\overline{(4)}$ \\
\hline Ln(Total UPG) & $\begin{array}{l}0.035^{* *} \\
(0.012)\end{array}$ & & & \\
\hline Ln(Net UPG) & & $\begin{array}{c}0.021^{* *} \\
(0.009)\end{array}$ & & $\begin{array}{c}0.027^{*} \\
(0.013)\end{array}$ \\
\hline Ln(Redefined) & & & $\begin{array}{c}0.007 \\
(0.007)\end{array}$ & $\begin{array}{c}0.012 \\
(0.009)\end{array}$ \\
\hline Ln(Residential Size pc) & $\begin{array}{c}0.020 \\
(0.028)\end{array}$ & $\begin{array}{c}0.021 \\
(0.035)\end{array}$ & $\begin{array}{c}0.009 \\
(0.026)\end{array}$ & $\begin{array}{c}0.048 \\
(0.041)\end{array}$ \\
\hline $\operatorname{Ln}(\mathrm{GDP} p c)$ & $\begin{array}{c}-0.037 \\
(0.109)\end{array}$ & $\begin{array}{l}-0.081 \\
(0.150)\end{array}$ & $\begin{array}{c}-0.043 \\
(0.096)\end{array}$ & $\begin{array}{c}-0.114 \\
(0.169)\end{array}$ \\
\hline Ln(Fiscal Income pc) & $\begin{array}{c}0.058 \\
(0.095)\end{array}$ & $\begin{array}{c}0.088 \\
(0.126)\end{array}$ & $\begin{array}{c}0.064 \\
(0.078)\end{array}$ & $\begin{array}{c}0.111 \\
(0.139)\end{array}$ \\
\hline Ln(Road Size pc) & $\begin{array}{c}-0.035^{* *} \\
(0.014)\end{array}$ & $\begin{array}{c}-0.039^{* *} \\
(0.018)\end{array}$ & $\begin{array}{c}-0.028^{*} \\
(0.014)\end{array}$ & $\begin{array}{c}-0.036^{* *} \\
(0.017)\end{array}$ \\
\hline $\operatorname{Ln}($ Green Size pc) & $\begin{array}{l}-0.012 \\
(0.019)\end{array}$ & $\begin{array}{l}-0.020 \\
(0.025)\end{array}$ & $\begin{array}{l}-0.013 \\
(0.020)\end{array}$ & $\begin{array}{l}-0.036 \\
(0.030)\end{array}$ \\
\hline Province FE & Yes & Yes & Yes & Yes \\
\hline$R^{2}$ & 0.241 & 0.243 & 0.214 & 0.259 \\
\hline Observations & 219 & 183 & 241 & 153 \\
\hline
\end{tabular}

Standard errors are clustered at the province level.

${ }^{*} p<0.1,{ }^{* *} p<0.05,{ }^{* * *} p<0.01$ 
Table 25: Surplus Index and Households with Urban Vacant Unit

\begin{tabular}{lcccc}
\hline \hline & Have Vacant & Have Vacant & No. Vacant & No. Vacant \\
\hline Surplus Index & $0.016^{* *}$ & $0.016^{* *}$ & $0.085^{* *}$ & $0.085^{* * *}$ \\
& $(0.007)$ & $(0.007)$ & $(0.034)$ & $(0.033)$ \\
Family Size & -0.002 & -0.002 & -0.010 & -0.010 \\
& $(0.004)$ & $(0.004)$ & $(0.020)$ & $(0.019)$ \\
Number of Children & -0.010 & $-0.010^{*}$ & -0.045 & -0.045 \\
& $(0.006)$ & $(0.006)$ & $(0.030)$ & $(0.032)$ \\
Number of Laborers & $0.020^{* * *}$ & $0.020^{* * *}$ & $0.100^{* * *}$ & $0.100^{* * *}$ \\
& $(0.004)$ & $(0.004)$ & $(0.021)$ & $(0.018)$ \\
Head Age & $-0.001^{* *}$ & $-0.001^{* *}$ & $-0.003^{* *}$ & $-0.003^{* *}$ \\
& $(0.000)$ & $(0.000)$ & $(0.001)$ & $(0.001)$ \\
Head Schooling & $0.005^{* * *}$ & $0.005^{* * *}$ & $0.026^{* * *}$ & $0.026^{* * *}$ \\
& $(0.001)$ & $(0.001)$ & $(0.005)$ & $(0.005)$ \\
Ln(Income) & $0.020^{* * *}$ & $0.020^{* * *}$ & $0.109^{* * *}$ & $0.109^{* * *}$ \\
& $(0.003)$ & $(0.003)$ & $(0.015)$ & $(0.016)$ \\
Ln(Consumption) & $0.054^{* * *}$ & $0.054^{* * *}$ & $0.289^{* * *}$ & $0.289^{* * *}$ \\
& $(0.005)$ & $(0.005)$ & $(0.023)$ & $(0.024)$ \\
Have Vehicle & $0.063^{* * *}$ & $0.063^{* * *}$ & $0.281^{* * *}$ & $0.281^{* * *}$ \\
City Tier Dummies & $(0.007)$ & $(0.007)$ & $(0.035)$ & $(0.035)$ \\
Bootstrap & Yes & Yes & Yes & Yes \\
\hline Observations & No & Yes & No & Yes \\
\hline \hline
\end{tabular}

For Probit estimation, marginal effects are displayed.

Number of replications with bootstrap standard errors are 100 .

${ }^{*} p<0.1,{ }^{* *} p<0.05,{ }^{* * *} p<0.01$ 